\title{
Mice Lacking Dystrophin or $\alpha$ Sarcoglycan Spontaneously Develop Embryonal Rhabdomyosarcoma with Cancer-Associated p53 Mutations and Alternatively Spliced or Mutant Mdm2 Transcripts
}

\author{
Karen Fernandez, ${ }^{*}$ Yelda Serinagaoglu, ${ }^{\dagger}$ \\ Sue Hammond, ${ }^{\ddagger \S}$ Laura T. Martin, ${ }^{+\uparrow}$ \\ and Paul T. Martin*9\|I \\ From the Division of Hematology/Oncology," the Center for Gene \\ Therapy, ${ }^{\dagger}$ and the Department of Pathology and Laboratory \\ Medicine, ${ }^{\ddagger}$ Nationwide Children's Hospital, Columbus, Obio; and \\ the Departments of Pathology, ${ }^{\S}$ Pediatrics, ${ }^{\text {II }}$ and Physiology and \\ Cell Biology," The Ohio State University College of Medicine, \\ Columbus, Obio
}

Altered expression of proteins in the dystrophin-associated glycoprotein complex results in muscular dystrophy and has more recently been implicated in a number of forms of cancer. Here we show that loss of either of two members of this complex, dystrophin in mdx mice or $\alpha$ sarcoglycan in $\mathrm{SgCa}^{-/-}$mice, results in the spontaneous development of muscle-derived embryonal rhabdomyosarcoma (RMS) after 1 year of age. Many $\mathrm{mdx}$ and $\mathrm{SgCa}^{-/-}$tumors showed increased expression of insulin-like growth factor 2 , retinoblastoma protein, and phosphorylated Akt and decreased expression of phosphatase and tensin homolog gene, much as is found in a human RMS. Further, all mdx and Sgca ${ }^{-/-}$RMS analyzed had increased expression of $p 53$ and murine double minute (mdm)2 protein and contained missense p53 mutations previously identified in human cancers. The mdx RMS also contained missense mutations in Mdm2 or alternatively spliced Mdm2 transcripts that lacked an exon encoding a portion of the p53-binding domain. No Pax3:Fkhr or Pax7:Fkhr translocation mRNA products were evident in any tumor. Expression of natively glycosylated $\alpha$ dystroglycan and $\alpha$ sarcoglycan was reduced in mdx RMS, whereas dystrophin expression was absent in almost all human RMS, both for embryonal and alveolar RMS subtypes. These studies show that absence of members of the dystrophin-associated glycoprotein complex constitutes a permissive environment for spontaneous development of embryonal RMS associated with mutation of $\mathrm{p} 53$ and mutation or altered splicing of Mdm2. (Am J Patbol 2010, 176:416-434; DOI: 10.2353/ajpath.2010.090405)

The dystrophin-associated glycoprotein (DAG) complex is a well-described group of muscle proteins whose loss of function causes muscular dystrophy. ${ }^{1-3}$ Aberrant expression or modifications of DAG proteins have more recently been associated with several types of cancer, suggesting that DAG proteins may also play a role in cancer biology. ${ }^{4,5}$ Here we demonstrate that mice with primary defects in the DAG complex develop embryonal rhabdomyosarcoma (ERMS), a soft tissue sarcoma of childhood that can emanate from skeletal muscle. ${ }^{6}$

As the name implies, the DAG complex is defined by the association of protein members with dystrophin. Dystrophin is a $427-\mathrm{kDa}$ cytoplasmic protein that is essential for anchoring the DAG proteins in the sarcolemmal membrane of skeletal myofibers and cardiomyocytes. ${ }^{7}$ In doing so, dystrophin links the muscle membrane to the extracellular matrix that surrounds each myofiber, via the

Supported by NIH grants AR050202 and AR047922 to P.T.M., and K.F. was supported by a fellowship sponsored by the Division of Pediatric Hematology and Oncology at Nationwide Children's Hospital.

K.F. and Y.S. contributed equally to this work.

Accepted for publication September 16, 2009

None of the authors have any conflicts of interest to declare, financial or otherwise. Tissue arrays were purchased from the Biopathology Core at Nationwide Children's Hospital after Institutional Review Board approval from Nationwide Children's Hospital and the appropriate Children's Oncology Group tumor subcommittee.

Address reprint requests to Paul T. Martin, Ph.D., Nationwide Children's Hospital, 700 Children's Drive, Columbus, OH 43205. E-mail: paul.martin@ nationwidechildrens.org. 
DAG complex, and to the cytoskeleton by direct binding to filamentous actin. Dystrophin binds the sarcolemmal membrane via its binding to dystroglycan, a central and essential member of the DAG complex. ${ }^{3,8}$ Dystroglycan is a complex of two polypeptides (termed $\alpha$ and $\beta$ dystroglycan) that are post-translationally cleaved from the same precursor protein. ${ }^{9} \beta$ dystroglycan is a transmembrane protein that can bind to or associate with cytoskeletal-associated proteins (including dystrophin, utrophin, ankyrin, and plectin $1^{10,11}$ ) and signaling proteins (including Grb2, rapsyn, src, Akt, mitogen-activated protein kinase ${ }^{5,12-17}$ ) via its intracellular domain and to $\alpha$ dystroglycan via its extracellular domain. $\alpha$ Dystroglycan, by virtue of binding to $\beta$ dystroglycan, is tightly (but noncovalently) linked to the extracellular face of the membrane and binds extracellular matrix proteins (including laminin, agrin, and perlecan) via interactions that require its heavily glycosylated mucin domain. ${ }^{18,19}$ Dystroglycan also associates with proteins within the membrane, including the sarcoglycans (which in skeletal muscle include $\alpha-, \beta-, \gamma-$, and $\delta$-sarcoglycan). Consistent with the importance of the DAG complex for maintaining membrane stability, mutations that lead to loss of dystrophin, sarcoglycans, laminin ( $\alpha 2)$, or to reduced glycosylation of $\alpha$ dystroglycan, cause forms of muscular dystrophy. ${ }^{20-25}$

Proteins within the DAG complex have recently been implicated in a number of cancers, ${ }^{26-31}$ including pediatric rhabdomyosarcoma (RMS). ${ }^{32}$ Aberrant underglycosylation of $\alpha$ dystroglycan, akin to what is seen in certain congenital and limb girdle muscular dystrophies, ${ }^{25}$ has been demonstrated both in pediatric ERMS and alveolar RMS (ARMS). ${ }^{32}$ Such loss of $\alpha$ dystroglycan glycosylation correlates with reduced laminin binding, however, the expression of $\beta$ dystroglycan, which is translated from the same gene, is unchanged. Thus, pediatric RMS shows a loss of $\alpha$ dystroglycan glycosylation but not dystroglycan protein expression. This finding is similar to studies of dystroglycan expression in other types of cancer, including cancer of the breast and colon, ${ }^{27,28,33-35}$ glioma, ${ }^{31}$ oral squamous cell carcinoma, ${ }^{30}$ and certain pediatric cancers such as neuroblastoma and medulloblastoma. ${ }^{32}$ Because dystrophin anchors both dystroglycan and sarcoglycans in the membrane, mice lacking dystrophin, including the mdx mouse, ${ }^{20,23}$ also have reduced expression of these proteins at the sarcolemmal membrane of skeletal myofibers. ${ }^{36}$ Similarly, DAG proteins are less stably associated with the membrane in the absence $\alpha$ sarcoglycan. ${ }^{37}$ Thus, such mouse models, in addition to being useful for the study of muscular dystrophy, may speak to the role of the DAG complex in tumorigenesis in cellular systems where its expression is altered.

Here, we show that mice lacking either dystrophin or $\alpha$ sarcoglycan develop ERMS with age. RMS is the most common soft tissue sarcoma of childhood and adolescence. ${ }^{38}$ The name rhabdomyosarcoma comes from the presence of skeletal muscle cells representing various stages muscle differentiation, from mononucleated myoblasts to multinucleated myotubes and rhabdomyoblasts, within the tumor. ${ }^{6}$ Immunostaining for muscle proteins, particularly MyoD, myogenin, and desmin, is used to aid in differentiating RMS from other types of sarcomas. ${ }^{39}$
While certain features of RMS are common, they comprise a highly heterogeneous group of tumors based on histopathology. The two major subtypes of pediatric RMS are ERMS and ARMS, although other subtypes (spindle cell RMS, botyroid RMS, anaplastic RMS, and pleiomorphic RMS) have also been described. ${ }^{40}$ Clinically, ERMS is more typically present at earlier ages, arises primarily from the head and neck, genitourinary tract, and retroperitoneum, and is associated with better clinical outcomes, while ARMS occurs more commonly in adolescents and adults, is more often identified in the trunk or extremities, and is associated with poorer treatment outcomes. ${ }^{6}$ ARMS is also associated with specific $t(1$; 13)(p36;q14) or $\mathrm{t}(2 ; 13)(\mathrm{q} 35 ; \mathrm{q} 14)$ chromosomal translocations between paired box (PAX)7 or PAX3 and forkhead in human rhabdomyosarcoma (FKHR), also known as FOXO1, ${ }^{41-43}$ respectively, while ERMS may contain deletions of $11 \mathrm{p} 15.5 .{ }^{44,45}$ Chromosomal translocations in ARMS lead to the expression of PAX3/FKHR or PAX7/FKHR fusion proteins that correlate with poorer treatment outcomes. ${ }^{46}$ Other oncogenes and cell cycle modulators, including TP53 and MDM2, ${ }^{47-51}$ cyclin-dependent kinase inhibitor (CDKN)2A, ${ }^{52-55} \mathrm{AKT},{ }^{56,57}$ phosphatase and tensin homolog (PTEN), ${ }^{58,59}$ survivin, $^{60,61}$ RAS, ${ }^{62} \mathrm{PTCH}^{63-65}$ SUFU, ${ }^{64,65}$ signal transducers and activator of transcription (STAT) $3{ }^{66}$ neurofibromatosis (NF)1, ${ }^{67}$ platelet derived growth factor receptor (PDGFR)-A, ${ }^{68}$ leukemia inhibitory factor (LIF), ${ }^{69} \mathrm{c}-m e t^{54,70}$ and insulin-like growth factor (IGF)2, ${ }^{71,72}$ have also been implicated in either ERMS or ARMS biology.

\section{Materials and Methods}

\section{Materials}

Antibodies to dystrophin (Dys1, mouse IgG2a to human amino acid [aa]1181-1388; Dys2, mouse IgG1 to human C-terminal 17aa; Dys3, mouse IgG2a to aa308-351), $\alpha$ sarcoglycan (a-Sarc, mouse IgG1 to rabbit aa217-289), and $\beta$ dystroglycan (43DAG, mouse IgG2a to human C-terminal 15aa) were purchased from Novo Castra (Newcastle On Tyne, UK). Antibody to glycosylated $\alpha$ dystroglycan (IIH6C4, 05-593, mouse IgM to glycosylated rabbit $\alpha$ dystroglycan) was purchased from Upstate Biotechnology (Lake Placid, NY). Antibody to MDM2 (Sc965, mouse mAb to human aa154-167), p53 (sc-100, mouse mAb to mouse aa88-93), MyoD1 (Sc-760, rabbit pAb to mouse full-length protein), myogenin (Sc-576, rabbit pAb to full-length rat myogenin), NF2 (Sc-332, rabbit pAb to human C-terminus), N-myc (Sc-971, rabbit pAb to human C-terminus), Pax 3/7 (Sc-25409, rabbit pAb to human Pax3 aa272-479 [C-terminus]), desmin (H-37, rabbit pAB to human aa15-90), Bax (Sc-6236, rabbit pAb to mouse aa1-171 of mouse $\mathrm{Bax} \alpha), \mathrm{BH} 3$ interacting domain death agonist (BID) (Sc-11423, rabbit pAb to human aa1-195), Bclll (Sc-783, rabbit pAb to human aa1-205), FKHR ( $\mathrm{H}-128$, rabbit $\mathrm{pAb}$ to human aa471-598), Rb (p110,Sc-102, mouse mAb to Rb- $\beta$ Gal fusion protein), and survivin (sc-10811, rabbit $\mathrm{pAb}$ to human aa1-142) were purchased from Santa Cruz Bio- 
technology (Santa Cruz, CA). Antibodies to Bclll (AF810, goat pAb to mouse aa1-208), apoptosis inhibiting factor (AF 1457, rabbit pAb to human aa121-613), Igf1 (AF791, goat IgG to mouse IGF-1), Igf2 (AF792, goat IgG to mouse IGF-II), and actin (AF4000, sheep pAb to human actin) were purchased from R\&D Systems (Minneapolis, MN). Antibodies to actin (A 5060, rabbit pAb to aa20-33) and desmin (DE-U-10, mouse mAb to pig full-length protein) were purchased from Sigma (St. Louis, MO). Antibody to Akt1-3 (9272, rabbit pAb to human Akt carboxyterminus), phospho-Akt (Ser473) (9271, rabbit pAb to human Akt phospho-serine 473), phospho-Akt (Thr308) (9275, rabbit pAb to human Akt phospho-threonine 308) were purchased from Cell Signaling Technology (Danvers, MA). Antibody to caspase-3 (31A1067, mouse mAb to human full-length protein, recognizes active cleaved fragments) was purchased from Alexis Biochemicals (San Diego, CA). Antibody to caspase 9 (JM-3136-100, rabbit pAb to human full-length protein) was purchased from MBL Polyclonal antibody (Watertown, MA). Antibody to glyceraldehyde-3-phosphase dehydrogenase (GAPDH, mouse IgG2b to rabbit GAPDH) was purchased from Chemicon (Temecula, CA). All relevant fluorescent- or enzyme-conjugated secondary antibodies were purchased from Jackson ImmunoResearch (West Grove, PA).

\section{Mice}

The mdx mice and $\mathrm{C} 57 \mathrm{BI} / 10$ littermates, and also $\alpha$ sarcoglycan-deficient (Sgca) mice and C57BI/6 littermates, were originally obtained from Jackson laboratories (Bar Harbor, ME). Some mdx mice were bred to either Galgt1 or Galgt2 knockout mice, which were on a pure bred C57BI/6 background. Galgt1 and Galgt2 deficient mice were obtained from the Consortium for Functional Glycomics (Scripps Research Institute, La Jolla, CA). Of these animals, only Galgt2 or Galgt1 heterozygous mdx mice were used for analysis (which were phenotypically indistinguishable from $\mathrm{mdx}$ mice and showed no failure to synthesize glycans normally made by Galgt1 or Galgt2 [not shown]). Some mdx mice were also bred to Cmahdeficient mice, which were bred on a pure C57BI/6 background. $\mathrm{Cmah}^{-1-}$ mice were a generous gift from Ajit Varki (UC San Diego). Again, only $\mathrm{Cmah}^{+/-} \mathrm{mdx}$ mice were considered in the analysis of tumorigenesis, and these were indistinguishable from $\mathrm{mdx}$ and showed no deficit in Neu5Gc, the sialic acid requiring Cmah activity (not shown). Wild-type animals were defined as any mouse from the colonies of $\mathrm{C} 57 \mathrm{BI} / 6$ or $\mathrm{C} 57 \mathrm{Bl} / 10$ mice, including Galgt2 ${ }^{+/-}$, Galgt1 ${ }^{+/-}, \mathrm{Cmah}^{+/-}$, and $\mathrm{Sgca}^{+/-}$ mice. All of these heterozygous mice behave as wild-type mice and have no overt phenotype (no change in muscle pathology, muscle physiology, lifespan, or ambulation). Mice were bred and cared for in a barrier facility and all animal care and experiments were done under protocols approved by the Institutional Animal Care and Use Committee at Nationwide Children's Hospital. Mice were checked daily for development of tumors.

\section{Human RMS Tissue Arrays}

Tissue microarray slides were obtained from the Biopathology Center at The Research Institute at Nationwide Children's Hospital after review by the Children's Oncology Group and after Institutional Review Board approval from Nationwide Children's Hospital. Tissue microarrays consisted of slides containing alveolar RMS (39 unique cases with 5 embryonal RMS and 5 normal muscle controls) or embryonal RMS (32 unique cases with 5 alveolar RMS and 5 normal muscle controls). Arrays contained one to three sections of the same tumor (ERMS or ARMS) and two to three sections of the same normal muscle spaced randomly throughout the slide.

\section{Histology}

For analysis of tumor morphology, tissue was excised after sacrifice, embedded in optimal cutting temperature compound (Sakura Finetek, Torrance, CA), and frozen in liquid nitrogen-cooled 2-methylbutane. Serial cryosections of $6 \mu \mathrm{m}$ thickness were cut and stained with H\&E, as previously described. ${ }^{32}$ Coverslips were positioned on the slides and attached using a drop of Permaslip (Alban Scientific, St. Louis, MO) and dried at room temperature overnight before viewing under a light microscope. Bright-field photographs were taken using a Zeiss Axioskop 40 microscope with AxioCamlCc3 camera system.

\section{Immunostaining of Mouse RMS}

Immunohistochemical staining for myogenin, MyoD, and desmin was performed by the avidin-biotin-complex peroxidase method. ${ }^{39}$ Briefly, $6-\mu \mathrm{m}$ cryosections of tumor tissue on slides were fixed in ice cold methanol for 3 minutes. Slides were incubated with avidin, biotin and $0.3 \% \mathrm{H}_{2} \mathrm{O}_{2} /$ PBS for 15 minutes each. Slides were washed with PBS between incubations. Tissue was blocked with $10 \%$ goat serum in PBS for 30 minutes at room temperature, followed by primary antibody [MyoD, myogenin, desmin (1:50) in PBS with 10\% goat serum overnight at $\left.4^{\circ} \mathrm{C}\right]$, biotin-labeled secondary anti-rabbit IgG for $30 \mathrm{~min}$ utes, and then horseradish peroxidase-conjugated streptavidin (Jackson ImmunoResearch; West Grove, PA) for 15 minutes. Slides were washed with PBS between incubations. Developing substrate (3-amino-9-ethylcarbazole) was added for 15 minutes, after which slides were counterstained with hematoxylin for 45 seconds and then quenched with ammonium hydroxide $0.25 \%$ for $30 \mathrm{sec}-$ onds. After drying of the slide, coverslips were positioned on the slides and attached using xylene-based mounting media. Immunofluorescence staining for $\alpha$ and $\beta$ dystroglycan and $\alpha$ and $\beta$ sarcoglycan was done as previously described on snap-frozen tumor or skeletal muscle tissue sectioned at $8 \mu \mathrm{m}$ on a cryostat. ${ }^{73}$ When possible, immunostaining was confirmed using more than one antibody made against the given protein. 


\section{Immunostaining of Human RMS Tissue Arrays}

Tissue microarray slides were deparaffinized in xylene, rinsed through three changes of $100 \%$ ethanol, and rehydrated in graded ethanol (95\% to $70 \%)$ and distilled water. Slides were subjected to antigen retrieval by incubation with $10 \mathrm{mmol} / \mathrm{L}$ sodium citrate, $\mathrm{pH}$. 6.0 for 30 minutes at $220^{\circ} \mathrm{C}$. Slides were then cooled and washed in PBS. Endogenous peroxidase activity was blocked by pre-incubation with 3\% hydrogen peroxide for 15 minutes, and slides were blocked by incubation in PBS with $10 \%$ goat serum for 1 hour at $25^{\circ} \mathrm{C}$. Primary antibody (Dys1 at 1:10 or Dys2 at 1:5) was added overnight. Slides were washed in PBS for 10 minutes and then incubated with horseradish peroxidase-conjugated anti-mouse IgG (1:100) diluted in 10\% goat serum/PBS for 1 hour. Slides were again washed in PBS for 10 minutes, after which they were developed for horseradish peroxidase activity using 3-amino-9-ethylcarbazole substrate for 40 minutes. Slides were then counterstained with hematoxylin for 45 seconds and quenched in ammonium hydroxide $0.25 \%$ for 30 seconds. Stained sections were covered with water-soluble mounting media and dried in warmer. Coverslips were positioned on the slides and attached using xylene based mounting media and dried at room temperature.

\section{Scoring of Human RMS Tissue Array Staining}

The extent of staining was scored blind with respect to case by three independent investigators. Scores were performed by eye using a Zeiss Axioskop 40 microscope with AxioCamlCc3 camera system microscope. Percentage of tumor cells with positive staining was scored as follows: 3 for $>75 \%$; 2 for $25 \%$ to $75 \%$; 1 for $5 \%$ to $25 \%$; and 0 for $<5 \%$. Scores were assessed only for tumor cells in ERMS and ARMS sections and only for myofibers in normal muscle sections. Almost all scores given 0 in fact had no detectable expression outside of normal skeletal muscle and endothelial cells present within the tumor section. On each microarray slide, particular tumors were represented in two to three independent regions. Scores were averaged to yield a single score for each tumor case. In some cases, estimates of percent staining by eye were confirmed using Zeiss AxioVision Rel 4.6 software to determine percentage area with stained tumor cells. These measurements always confirmed the tumor score given.

\section{Immunoblotting}

Tumor and control tissue lysates were prepared from tumor specimens and from mouse skeletal muscle (gastrocnemius) dissected from wild-type or mdx mice. Total cell lysates were made by homogenization of tissue in buffer containing $75 \mathrm{mmol} / \mathrm{L}$ Tris (pH 6.8), 2 mmol/L EDTA, 2\% NP40, 1\% glycerol, and 1:200 protease inhibitor cocktail containing phenylmethylsulfonyl fluoride, aprotinin, bestatin, and leupeptin (Sigma; St. Louis, MO). Each sample was diluted, and protein concentration measured in triplicate using the Bio-Rad (Richmond, CA) DC protein assay kit. The total amount of protein (20 or 40 $\mu \mathrm{g} /$ well) needed to load each well was mixed with SDS loading buffer containing $\beta$-mercaptoethanol (1:50) and heated at $95^{\circ} \mathrm{C}$ for 2 minutes. Protein samples were loaded in equal amounts and separated by SDS-polyacrylamide gel electrophoresis (PAGE). The proteins were transferred to a nitrocellulose membrane and tested for various antibodies by Western blot as previously described. ${ }^{73}$ Proteins were quantified by densitometric scanning of blots as previously described. ${ }^{73}$

\section{Endpoint Reverse Transcription-PCR and TaqMan Quantitative Reverse Transcription-PCR}

RNA from mdx RMS or Sgca ${ }^{-1-}$ RMS or from normal wildtype and mdx skeletal muscles (gastrocnemius or quadriceps) was extracted using the Trizol reagent (15596-026, Invitrogen, Carlsbad, CA) according to the manufacturer's instructions and further purified on a silica gel-based membrane (RNeasy Mini Kit, 74104, Qiagen, Valencia, CA). RNA content was measured using an ND-1000 spectrophotometer (Nanodrop, Wilmington, DE). RNA integrity was determined by capillary electrophoresis using 6000 Nano LabChip kit on a Bioanalyzer 2100 (Agilent, Foster City, CA). Only samples with no evidence of degradation were used. A high-capacity cDNA Reverse Transcription kit (4368813, Applied Biosystems, Foster City, CA) was used to reversetranscribe $0.6 \mu \mathrm{g}$ total RNA using Oligo $\mathrm{d}(\mathrm{T})_{16}$ primers (N8080128, Applied Biosystems, Foster City, CA), for endpoint reverse transcription (RT)-PCR, and random primers for quantitative (q)RT-PCR, in a $20 \mu$ l-reaction following the manufacturer's instructions. For endpoint RT-PCR, $1 \mu \mathrm{l}$ of each sample was used to amplify Pax3/7, Fkhr, p53, Mdm2, and $\beta$ Actin cDNAs separately. PCRs were performed using recombinant TaqDNA polymerase (10342-020, Invitrogen, Carlsbad, CA) following the manufacturer's instructions. The primers used were mPax3/7-F1 (5'-AGTGTCCACCCCTCTTGGCC-3') and mPax3/7-R1 (5'-ACAGGGTCCACACTGTAGCC-3') for Pax3/7; mFkhr-F1 (5'-GAGTTTAACCAGTCCAACTCG-3') and mFkhr-R2 (5'-GTAGTCTTGACACTGTGTGGG-3') for forkhead (Fkhr); $\beta A-F$ (5'GCATGTGCAAAGCCGGCTTC-3'), and $\beta A-R\left(5^{\prime}-\right.$ GGGGTGTTGAAGGTCTCAAA-3') for $\beta$ actin; mp53-F1 5'-TCCGAAGACTGGATGACTGC-3' (in Exon 2) and mp53-R1 5'-CTTGGTCTTCAGGTAGCTGG-3' (at the junction of Exons 10 and 11b) for p53; and m-mdm2-F1 5'-GAAGTAGCAGCCGTCTGCTG-3' (at the junction of Exons 1 and 2) and m-mdm2-R1 5'-GGATTGGCTGTCTGCACACTGG-3' (in Exon 12) for Mdm2. Pax3/7, Fkhr, and 5'Pax3/7:3'Fkhr PCRs were done using a touchdown protocol beginning at $62^{\circ} \mathrm{C}$ for the annealing temperature and decreasing by $0.5^{\circ} \mathrm{C}$ each cycle until $55^{\circ} \mathrm{C}$. PCRs for p53, Mdm2, and $\beta$ actin were done at constant annealing temperature of $55^{\circ} \mathrm{C}$. The bands were resolved in $0.8 \%$ agarose gel in $1 \times$ Trisacetate buffer. Gel pictures were taken using the Flu- 
orChem 8900 gel documentation system ( $\alpha$ Innotech, San Leandro, CA).

For TaqMan qRT-PCR, cDNA was reverse transcribed as above, only using random primers. Real-Time PCR measurements were performed in triplicate for each sample using the Applied Biosystems 7500 Real-Time PCR system (Applied Biosystems, Foster City, CA) with 18S ribosomal RNA (4308329, Applied Biosystems, Foster City, CA) as internal control. Primers and probes for the genes of interest (Trp53-Mm01731290_g1, exons 5-6; Pax3Mm00435493_m1, exons 7-8; Pax7-Mm03053796_s1, exon 9; Fkhr- Mm00490671_m1, exons 1-2; Mdm2Mm00487656_m1, exons 9-10) were purchased as ready to use $20 \times$ TaqMan assays from Applied Biosystems. Each $25 \mu$ l PCR mix contained $2.5 \mu$ l of 1:100 diluted cDNA, $1 \times$ TaqMan assay, and $1 \times$ TaqMan Universal PCR master mix (4304437, Applied Biosystems). After an initial hold of 2 minutes at $50^{\circ} \mathrm{C}$ to allow activation of AmpErase and 10 minutes at $95^{\circ} \mathrm{C}$ to activate the AmpliTaq polymerase, the samples were cycled 40 times at $95^{\circ} \mathrm{C}$ for 15 seconds and $60^{\circ} \mathrm{C}$ for 1 minute. Relative changes in gene expression were determined by the $2^{-\Delta \Delta \mathrm{Ct}}$ method $^{74}$ using $18 \mathrm{~S}$ ribosomal RNA as a control. All measurements were done in triplicate for each data point.

\section{Cloning and Sequencing of p53 and Mdm2 cDNA Fragments}

cDNA fragments derived from endpoint RT-PCR were resolved in $1 \%$ agarose gel in $1 \times$ TAE buffer. Pfu Turbo DNA polymerase (600250, Stratagene, La Jolla CA) was used to amplify cDNAs using the same primers used for RT-PCR (which encompass the region where cancer-associated mutations most often occur, exons 2-10 in p53 (PubMed Accession \#: NM_011640) or the full length Mdm2 transcript (exons 1-12, PubMed Accession \#:NM_010786). Oligonucleotide sequences used for amplification are specified in the RT-PCR Methods section. Fragments were gel-extracted using Qiagen gel extraction kit (28704, Qiagen, Inc., Valencia, CA) and cloned into pCR 2.1-TOPO vector using the TOPO TA cloning kit (K4500-01, Invitrogen, Carlsbad, CA). Multiple colonies were picked and sequenced from 7 mdx RMS (total of 25 p53 and 18 Mdm2 clones) and from 7 age-matched normal mdx (gastrocnemius) skeletal muscle (total of 18 p53 clones and $22 \mathrm{Mdm} 2$ clones). Plasmids were first purified and screened for the p53 or Mdm2 cDNA insert before

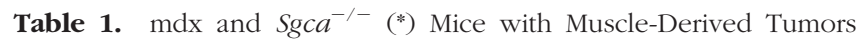

\begin{tabular}{|c|c|c|c|c|c|}
\hline Sample & Sex & Age (months) & Body weight (g) & Tumor weight (g) & Tumor location \\
\hline 1 & $F^{*}$ & 12 & 35.0 & 4.8 & Hindlimb \\
\hline 2 & $\mathrm{M}$ & 12 & 34.1 & 8.0 & Forelimb \\
\hline 3 & $M$ & 12 & 42.2 & 10.6 & Paraspinal \\
\hline 4 & $\mathrm{~F}$ & 12 & 31.2 & 2.9 & Forelimb \\
\hline 5 & $\mathrm{M}$ & 13 & 25.0 & 3.3 & Hindlimb \\
\hline 6 & $\mathrm{M}$ & 13 & 25.2 & 2.3 & Hindlimb \\
\hline 7 & $M$ & 14 & 36.1 & 8.2 & Hindlimb \\
\hline 8 & $\mathrm{~F}^{*}$ & 14 & 31.8 & 0.6 & Hindlimb \\
\hline 9 & $F^{*}$ & 15 & 28.4 & 0.3 & Hindlimb \\
\hline 10 & $\mathrm{~F}$ & 15 & 27.8 & 0.8 & Forelimb \\
\hline 11 & $\mathrm{~F}$ & 16 & 33.6 & 9.4 & Hindlimb \\
\hline 12 & $\mathrm{M}$ & 16 & 38.3 & 6.4 & Forelimb \\
\hline 13 & $M$ & 16 & 24.9 & 0.7 & Hindlimb \\
\hline 14 & $\mathrm{M}$ & 16 & 35.4 & 5.8 & Hindlimb \\
\hline 15 & $\mathrm{M}$ & 16 & 30.0 & 1.8 & Hindlimb \\
\hline 16 & $\mathrm{M}$ & 17 & 33.8 & 5.3 & Forelimb \\
\hline 17 & $\mathrm{M}$ & 17 & 32.4 & 4.0 & Forelimb \\
\hline 18 & $M^{*}$ & 17 & 34.0 & 11.1 & Forelimb \\
\hline 19 & $\mathrm{M}$ & 18 & 36.7 & 4.0 & Paraspinal \\
\hline 20 & $\mathrm{~F}$ & 18 & 27.0 & 1.9 & Forelimb \\
\hline 21 & $M$ & 18 & 25.0 & 2.5 & Forelimb \\
\hline 22 & $M$ & 19 & 31.9 & 0.9 & Hindlimb \\
\hline 23 & $\mathrm{~F}$ & 19 & 26.4 & 2.5 & Forelimb \\
\hline 24 & $\mathrm{M}$ & 19 & 18.6 & 3.3 & Back \\
\hline 25 & $M$ & 19 & 34.1 & 1.2 & Forelimb \\
\hline 26 & $\mathrm{M}$ & 19 & 30.1 & 0.9 & Forelimb \\
\hline 27 & $M$ & 19 & 25.0 & 3.2 & Forelimb \\
\hline 28 & $M$ & 19 & 33.5 & 6.9 & Forelimb \\
\hline 29 & $M$ & 21 & 31.2 & 1.7 & Hindlimb \\
\hline 30 & $\mathrm{M}$ & 23 & 35.0 & 2.7 & Forelimb \\
\hline 31 & $\mathrm{~F}$ & 23 & 34.2 & 3.2 & Hindlimb \\
\hline 32 & $\mathrm{~F}$ & 24 & 17.9 & 0.8 & Periorbital \\
\hline 33 & $\mathrm{M}$ & 24 & 33.0 & 5.4 & Forelimb/chest \\
\hline 34 & $\mathrm{~F}$ & 27 & 22.4 & 1.4 & Forelimb \\
\hline 35 & $\mathrm{M}$ & 21 & 26.2 & 2.4 & Paraspinal \\
\hline 36 & $\mathrm{M}$ & 21 & 36.1 & 6.4 & Hindlimb \\
\hline
\end{tabular}

*Indicates $\mathrm{Sgca}^{-/-}$animals. 
sequencing. Positive clones were sequenced along the entire length of amplified clones. M13 Reverse and Forward primers were used for DNA sequencing reactions. Due to length, a third internal sequencing oligonucleotide, 5'-AGATGAGCTACCTGGGGAGC-3', was also used for Mdm2. Sequences were analyzed by ClustalW2 to determine homology between mouse and human p53 or Mdm2 gene sequences and then compared with mutations present in the IARC TP53 database (version R13, accessed on April 29, 2009, http://www-p53.iarc.fr/). ${ }^{75}$

\section{Statistics}

Determinations of significance between RMS and normal mdx samples were done using an unpaired Student's $t$-test with equal weighting between samples. Where appropriate, comparison of significance between more than two groups was done using analysis of variance with pre- and posthoc Bonferroni analysis. Odds ratio determination was done to compare tumor incidence using GraphPad Prism 4.03 software (GraphPad, La Jolla, CA).

\section{Results}

\section{Spontaneous Development of ERMS in a} Subset of Aged Dystrophin-Deficient ( $m d x$ ) and $\alpha$ Sarcoglycan-Deficient $\left(\right.$ Sgca $^{-/-}$) Mice

In performing lifespan studies of particular gene deletions in mdx mice, we had allowed a significant number of mdx mice, 350, to age to a year or older. Here, only wild-type $\mathrm{mdx}$ animals or mice heterozygous for a second gene deletion (Galgt1, Galgt2, or Cmah) were used. These other genes control synthesis of $\beta 1,4$ GalNAc linkages on Neu5Ac $\alpha 2,3 \mathrm{Gal} \beta 1,4$-linked glycans on glycoproteins (Galgt2) ${ }^{76}$ or on gangliosides (Galgt1 $)^{77,78}$ or control the synthesis of a specific modification (5-hydroxylation) of sialic acid (Cmah).$^{79}$ While mice with a homozygous deletion of these genes show deficits in the glycans they create and have resulting phenotypes, including altered wound healing and hearing deficits (in Cmah-deficient mice ${ }^{79}$ ) and age-dependent Wallerian degeneration of peripheral nerves (in Galgt1-deficient mice ${ }^{77}$ ), such mice with only a heterozygous deletion, as used here, show normal levels of glycan expression in skeletal muscle and no phenotypes that distinguish them from normal $\mathrm{mdx}$ animals (equivalent muscle pathology and physiology, lifespan, and ambulation [not shown]). These $\mathrm{mdx}$ mice were compared with equivalent numbers of strain-matched C57BI/6 or C57BI/10 wild-type mice. Again, some of these control animals were heterozygous for the afore-mentioned gene deletions bred into the mdx colony, and again such animals showed no glycosylation deficit and no phenotype (absence of muscle pathology, unchanged lifespan, unchanged locomotor and muscle strength measures [not shown]). Of the $350 \mathrm{mdx}$ mice allowed to age to one year or more, 32 mdx animals, or $9 \%$ of the total, developed skeletal mus- cle-derived tumors (Table 1). By contrast, not one of 450 similarly aged wild-type mice developed such musclederived tumors. Tumor incidence in $\mathrm{mdx}$ animals was proportionate to the number of animals with each secondary genotype (Galgt2 ${ }^{+/-}$, Galgt1 ${ }^{+/-}$, or $\mathrm{Cmah}^{+/-}$[not shown]). In addition, 4 of $80(5 \%)$ mice deficient in $\alpha$ sarcoglycan $\left(\mathrm{Sgca}^{-1-}\right)$ developed skeletal muscle-derived tumors, compared with none in the heterozygous and wild-type colonies (Table 1). These mice contained no secondary genetic changes. Control (nondystrophic, wild-type) mice did develop tumors outside the musculature at a low incidence, including tumors derived from the liver, ovary, and spinal cord (not shown). Thus, control animals were not immune to developing cancer, but showed no muscle-derived tumors, while there was a significant increase in muscle-derived tumors in $\mathrm{mdx}$ and Sgca ${ }^{-1-}$ strains of mice $(P<0.001$, two-tailed unpaired $t$-test for $\mathrm{mdx}$ or $\mathrm{Sgca}^{-1-}$ compared with wild-type). The odds ratio of mdx mice for RMS development was 81 (to wild-type), while it was 47 for Sgca ${ }^{-1-}$ (to wild-type).

Tumors arose from skeletal muscles throughout the body axis, but were primarily axial in origin (Table 1 and Figure 1, A-E). Muscles identified with tumors directly emanated from them were the trapezius, quadriceps, gastrocnemius, tibialis anterior, biceps, triceps, and the muscles of the periorbital region. Once identified, tumors grew at a dramatic rate, and mice had to be sacrificed
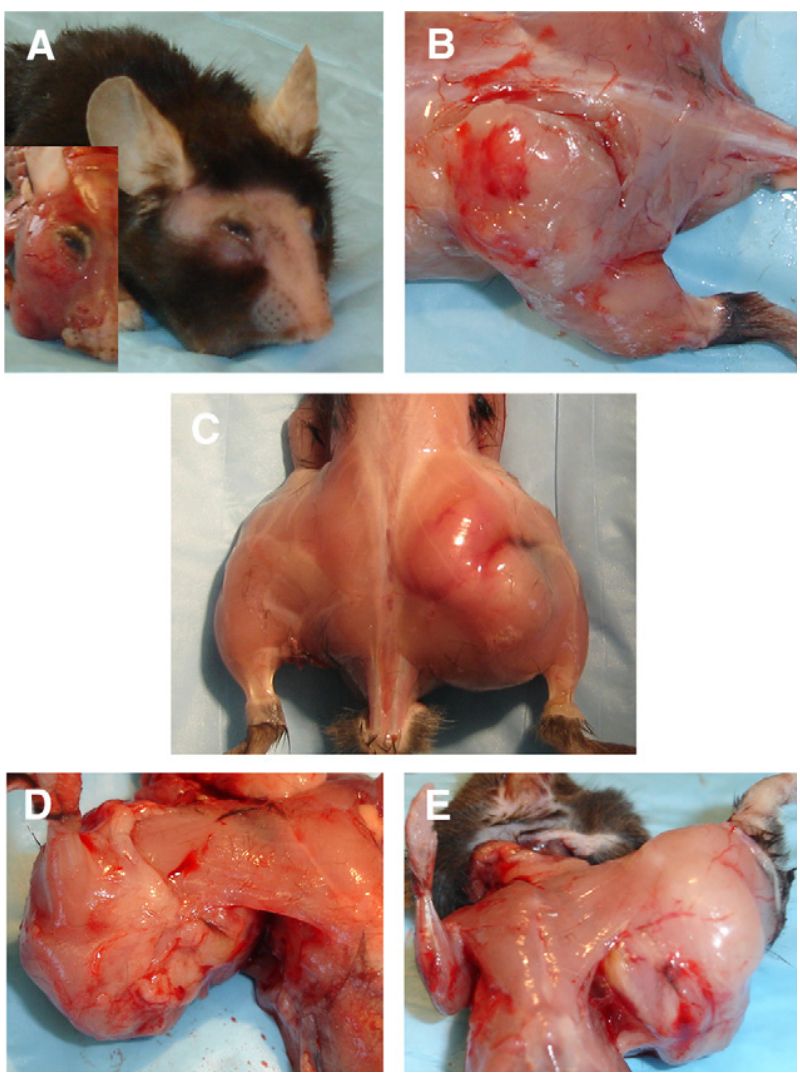

Figure 1. $\mathrm{mdx}$ and $\mathrm{Sgca^{-/- }}$ mice develop skeletal muscle-derived tumor with age. Mice lacking dystrophin ( $\mathrm{mdx}$ ) or $\alpha$ sarcoglycan $\left(\mathrm{SgCa}^{-/-}\right)$developed skeletal muscle-derived tumors, primarily from the axial musculature, after 12 months of age. Examples of tumors emanating from periorbital muscles (A), muscles in the hindlimb/buttocks $(\mathbf{B}, \mathbf{C})$, or forelimb muscles $(\mathbf{D}, \mathbf{E})$ are shown. 

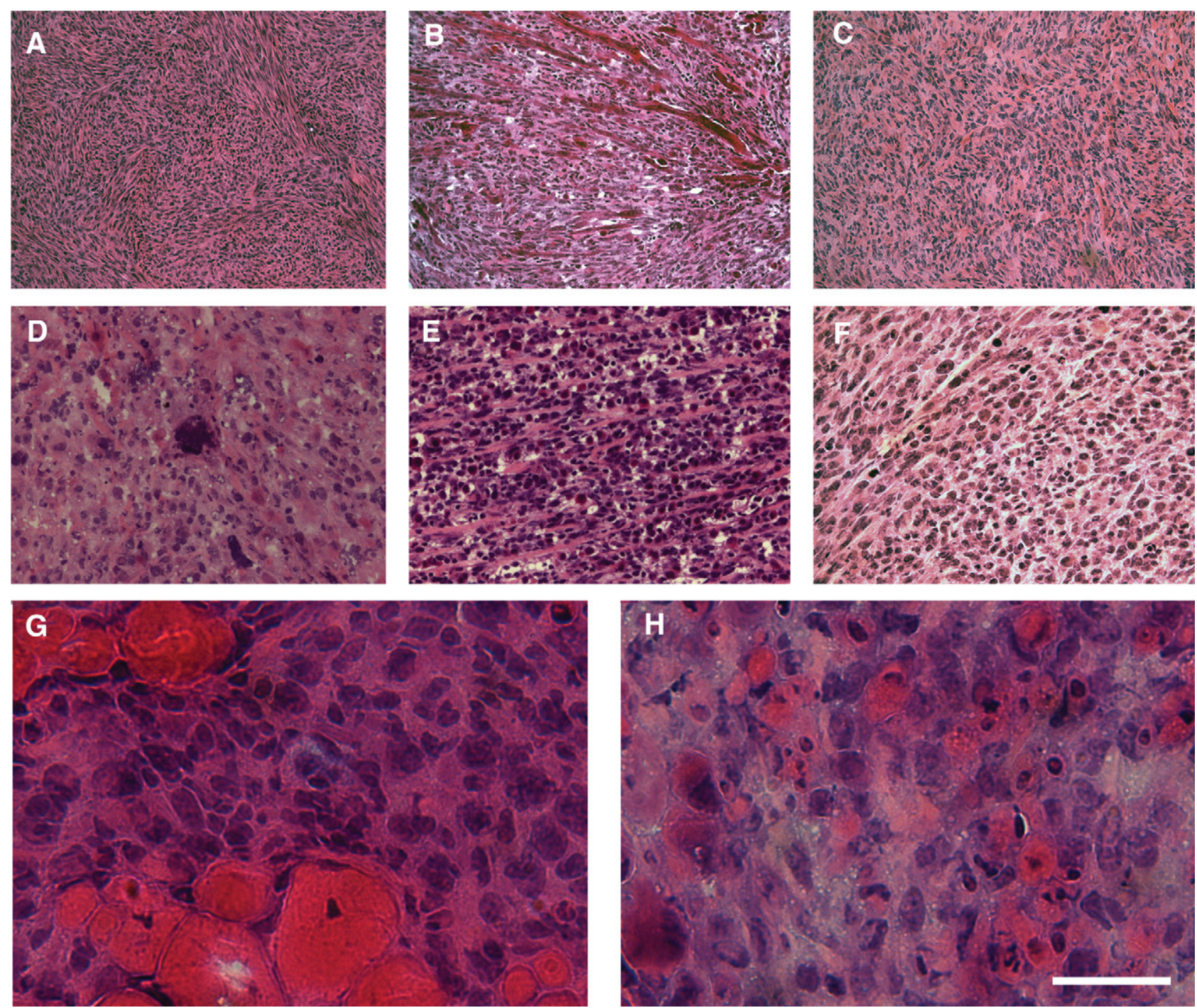

Figure 2. $\mathrm{mdx}$ and $\mathrm{SgCa}^{-/-}$tumors are embryonal rhabdomyosarcoma. Tumors were snap-frozen, cut, and stained with H\&E. All tumors showed characteristics of embryonal rhabdomyosarcoma, including high cellularity (A-C, F) with evidence of muscle differentiation (B). A small fraction of tumors showed anaplasia (D) and a few contained very small areas (ca. 1\% of total) with an alveolar-like pattern (E). RMS cells were present within regions bounded by and containing dystrophic skeletal myofibers (G) and often contained rhabdomyoblasts (H). Scale bars: $200 \mu \mathrm{m}(\mathbf{A}-\mathbf{C}), 100 \mu \mathrm{m}(\mathbf{D}-\mathbf{F})$, and $50 \mu \mathrm{m}(\mathbf{G}-\mathbf{H})$.

within 1 to 2 weeks after identification of a tumoral mass. Tumors ranged in size, but frequently exceeded $10 \%$ of total body weight (Table 1). No obvious metastatic lesions were visible on gross inspection of other organs, however, a few mice were noted to have regional hyperplastic lymph nodes.

Tumors were snap-frozen, sectioned on a cryostat, and stained with $\mathrm{H} \& \mathrm{E}$ (Figure 2, A-H). All tumors were analyzed and diagnosed as ERMS (Figures 2 and 3). All cases showed moderate to high cellularity with round or spindle-shaped cells in roughly equal numbers. Some, but not all, spindle cases had an overall storiform pattern (Figures 2, A and C). A minority of tumors (4 of 32) showed anaplasia (Figure 2D), which is associated with poorer prognosis in human $\mathrm{RMS},{ }^{5}$ or multinucleated tumor cells. No cases had an alveolar pattern, though several tumors (two) had very small areas with an alveolar-like morphology (but comprising less than 1\% of total tumor area) where tumor cells appeared to be aligned along strands of extracellular matrix (Figure 2E). All cases showed evidence of muscle differentiation that varied from round cells with abundant cytoplasm indicative of rhabdomyoblasts (Figure $2 \mathrm{H}$ ), a hallmark of RMS, to myotube-like formations (Figure 2B). Skeletal myofibers were often present within regions of tumor growth and always at its borders (Figure 2G). Because many of these myotubes resulted from regenerative processes, they contain centrally localized nuclei, a hallmark of regenerating myofibers in dystrophic rodents. ${ }^{80}$ About one third of all tumors contained regions of significant tumor necrosis.

RMS is typically defined by a combination of cellular and molecular characteristics, including expression of the myogenic differentiation factors myogenin and MyoD, as well as the muscle intermediate filament protein desmin. ${ }^{39}$ Accordingly, tumors were stained with antibodies that recognize mouse desmin, MyoD, or myogenin (Figure 3). All tumors were found to express each of these proteins in a subset of tumor cells, helping to define 


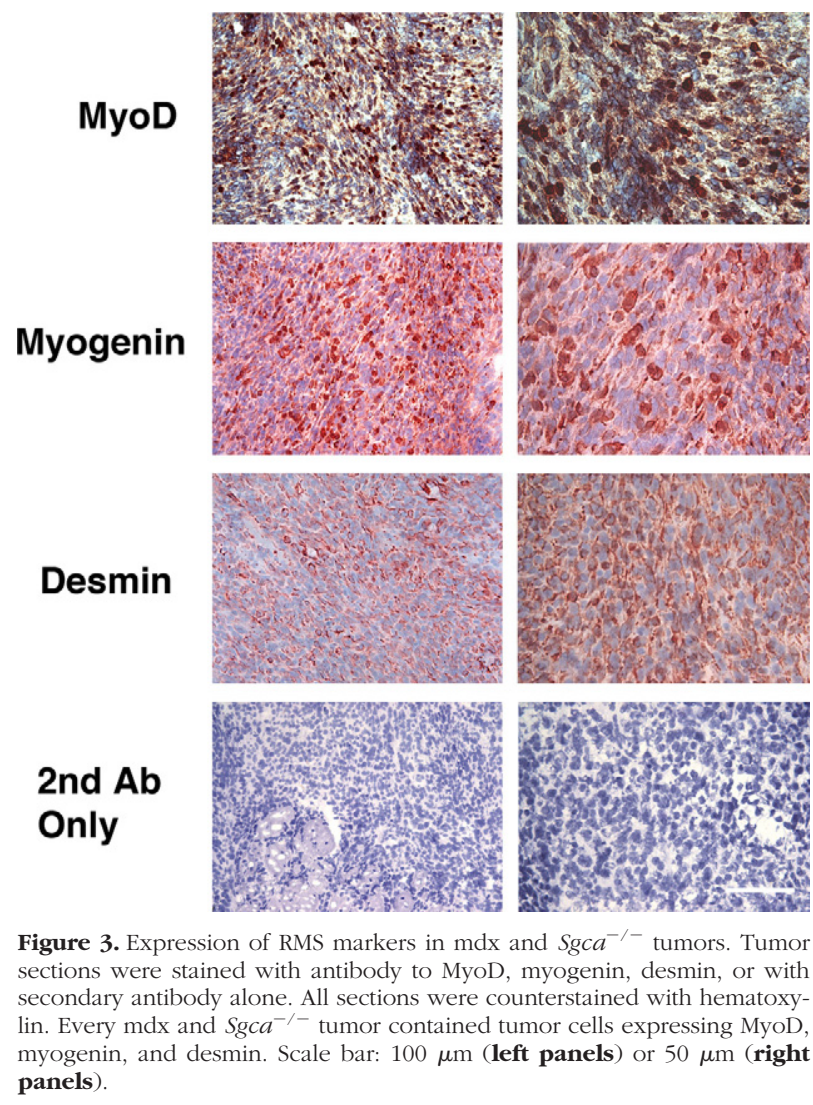

all cases as RMS. While there was some background staining for MyoD and myogenin in regions outside the nucleus, a finding typically found and considered nonspecific, ${ }^{39}$ we found high (specific) nuclear staining for both of these antibodies in a subset of tumor cells in all tumors analyzed. Staining for desmin, an intermediate filament protein, was entirely cytoplasmic and showed no nuclear staining, as expected, while secondary antibody alone yielded no staining in any tumor. While some regions showed a high co-incidence of MyoD and myogenin staining in tumor cells (20\% to $40 \%$ ) (Figure 3), other regions within the same tumors showed much lower incidence $(<10 \%)$, which is more typical of ERMS than of ARMS. ${ }^{39}$ Incidence of desmin staining was high in all regions of all tumors (>90\%).

\section{Molecular Characterization of RMS-Like Changes in mdx RMS}

Human RMSs typically have altered expression of a number of oncogenes, and the majority of ARMS also show specific chromosomal translocations between PAX3 or PAX7 and FKHR. Such changes, while never absolute in terms of incidence, have been well-documented. ${ }^{6,43,48}$ We assessed many of these molecular changes in $\mathrm{mdx}$ RMS by extracting whole cell protein and comparing expression with protein extracts isolated from normal $m d x$ and wild-type skeletal muscle using immunoblotting (Figure 4). Because mouse Pax3 and Pax7 are so similar in protein sequence, we used an antibody to a region of

\section{WT mdx mdx RMS}

Pax3/7
(C-terminal)

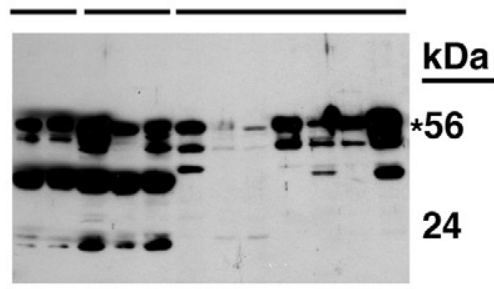

Fkhr
(C-terminal)

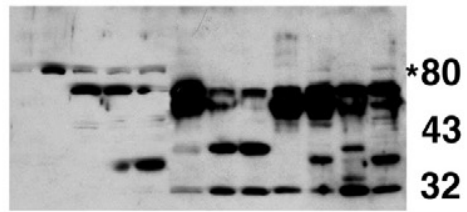

p53

53

$\mathbf{R b}$

Mdm2

Igf1

Igf2

Akt (protein)

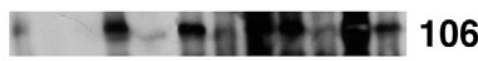

Akt (p-Thr)

Akt (p-Ser)

PTEN

Survivin

Desmin

Actin

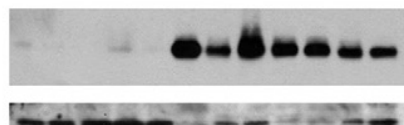

90

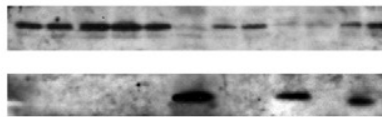

24

18

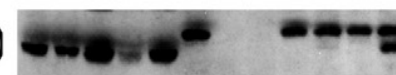

60
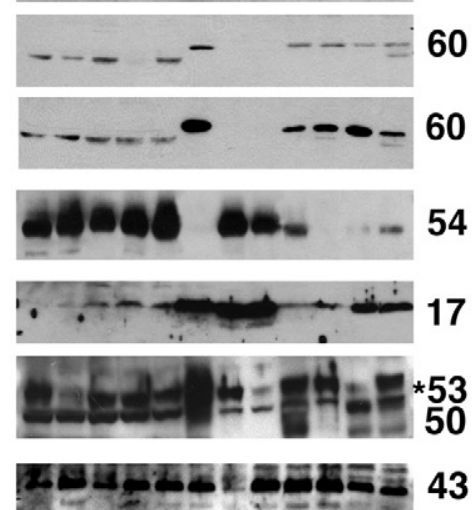

2nd Ab
Only

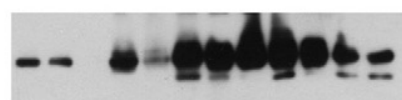

Figure 4. Expression of cancer-related proteins in mdx RMS and normal mdx and wild-type (WT) skeletal muscle. Forty micrograms of whole muscle protein lysate from wild-type skeletal muscle (WT), mdx skeletal muscle ( $m d x)$, or mdx RMS tumor (mdx RMS) were separated on SDS-PAGE gels and blotted with the indicated antibodies. All mdx RMS overexpressed p53 and Mdm2, while some, but not all, mdx RMS overexpressed Igf2, phosphoserine473-Akt, survivin, and $\mathrm{Rb}$ or had reduced levels of PTEN. Native molecular weights, indicated by asterisks when multiple bands were present, are: Pax3/7 (56 kDa), Fkhr (80 kDa), p53 (53 kDa) Rb (106 kDa), Mdm2 (90 kDa), pre-pro IGF1 (24 kDa), pre-pro IGF2 (18 kDa), Akt (60 kDa), PTEN (54 kDa), survivin (17 kDa), desmin (53 kDa), and actin ( $43 \mathrm{kDa})$.

homology between the two proteins to simultaneously characterize Pax3 and Pax7 expression (or Pax3/7). Both wild-type and mdx muscles expressed full-length Pax3/7 protein $(56 \mathrm{kDa})$. This was expected, as Pax7 is a molecular marker for intramuscular satellite cells, ${ }^{81}$ which 


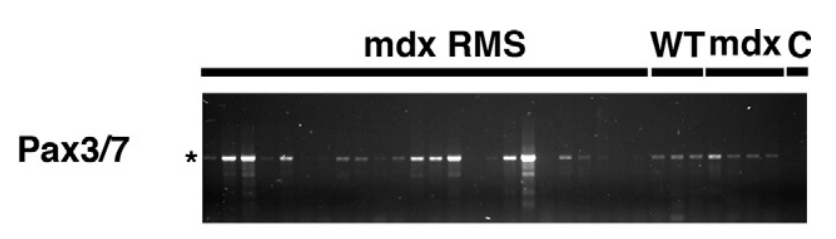

Fkhr

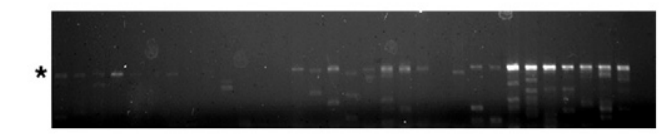

Pax3/7 5' Fkhr 3'

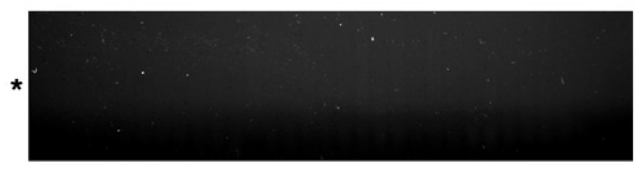

BActin

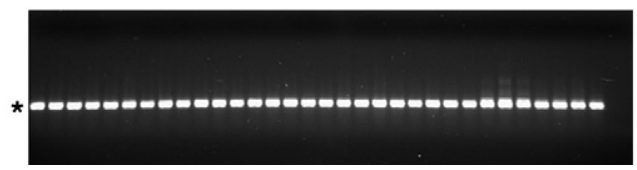

Figure 5. mRNA levels for Pax3/7, Fkhr, and possible Pax3/7-Fkhr translocation products in mdx RMS. mRNA for Pax3 and Pax7 (cumulative, Pax3/7), Fkhr, and potential 5' Pax3/7-3'Fkhr translocation products were assessed by endpoint RT-PCR, compared with $\beta$ actin control, in mdx RMS tumors and wild-type (WT) and mdx skeletal muscle. C is control with no template added. Asterisks indicate the expected molecular weight of full-length amplified cDNA.

would be present in normal and dystrophic skeletal muscle. ${ }^{81} \mathrm{mdx}$ RMS expressed Pax3/7 and Fkhr, as did wildtype and mdx skeletal muscle (Figure 4). Mouse Fkhr protein in mdx RMS was often of lower molecular weight than the native protein $(80 \mathrm{kDa})$, suggesting these tumors may have altered processing of Fkhr that may lead to expression of inactive or dominant-negative protein fragments. Alternatively, some such bands may reflect nonspecific binding of the primary antibody. No higher molecular weight fragments (>80 kDa) were present, however, that would be indicative of expression of Pax3/7Fkhr fusion proteins.

We confirmed the lack of human ARMS-like Pax3/7Fkhr translocations by RT-PCR (Figure 5). Primers were used that recognize regions at the $5^{\prime}$ and $3^{\prime}$ ends of both Pax3 and Pax7 (using oligos that anneal to regions of complete homology between the two genes). A minority of $\mathrm{mdx}$ RMS showed increased expression of Pax3/7 mRNAs (Figure 5). These data were quantified by TaqMan qRT-PCR (Table 2). These studies showed highly variable changes in Pax 3 or Pax 7 gene expression in $\mathrm{mdx}$ RMS; 6 of 25 mdx RMS showed elevations in excess of 10-fold for Pax3, relative to wild-type skeletal muscle, and 6 of 25 tumors showed elevation in excess of 10-fold for Pax7. The majority of mdx RMS, however, showed a less than twofold change for both genes (not shown). Interestingly, only one of the tumors showing highly elevated Pax3 also showed highly elevated Pax7. Additionally, Pax3 showed increased expression in normal muscle with age (both wild-type and $\mathrm{mdx}$ ), while Pax7 showed decreased expression (Table 2). Despite these changes in normal muscle, both Pax3 and 7 were, on average, significantly elevated in $\mathrm{mdx}$ RMS relative to agematched normal mdx muscle, while Fkhr was not (Table 2). Fkhr, however, did show decreased expression in normal mdx skeletal muscle (both young and old) compared with age-matched wild-type. Nevertheless, none of the $25 \mathrm{mdx}$ RMS analyzed showed greater than twofold elevation in Fkhr expression compared with agedmatched mdx controls. $\beta$ actin (Figure 5) or 18S RNA (Table 2) were run as controls to verify that a similar amount of RT product was present for mRNA analysis.

Before analyzing Pax:Fkhr translocation products, primers to the $5^{\prime}$ and $3^{\prime}$ ends of mouse Fkhr were used to amplify near full-length Fkhr transcripts. As expected based on qRT-PCR measurements, most $\mathrm{mdx}$ RMSs expressed Fkhr mRNA, though at reduced levels compared with normal (young) mdx muscle (Figure 5), which again was consistent with qRT-PCR (Table 2). Some low molecular PCR products were also present in this PCR that could not be removed by optimizing annealing conditions (Figure 5). The Fkhr band of the expected molecular weight (Figure 5) was excised from some reactions and verified as Fkhr by DNA sequencing (not shown). To identify transcripts that would emanate only from human-like Pax3:Fkhr or Pax7:Fkhr translocations, we used the $5^{\prime} \mathrm{Pax} 3 / 7$ and $3^{\prime} \mathrm{Fkhr}$ primers to amplify potential transcripts that would result from such human RMS-like translocations. We found no expression of any such transcripts that would indicate a Pax3:Fkhr or Pax7: Fkhr chromosomal translocation had occurred (Figure 5). These same oligos, however, when used in a different pairing, did amplify Pax3/7 or Fkhr (Figure 5), suggesting the negative result was reflective of an absence of Pax3/7:Fkhr translocation products rather than a nonspecific absence of oligonucleotide binding. This finding is consistent with the diagnosis of embryonal RMS in mdx tumors, as most alveolar RMS cases in humans

Table 2. TaqMan qRT-PCR Measurements of Changes in p53, Mdm2, Pax3, Pax 7 , and Fkhr Gene Expression in mdx RMS Compared with Normal Wild-Type and mdx Skeletal Muscle

\begin{tabular}{lccccc}
\hline Gene & WT (young) & mdx (young) & WT (old) & mdx (old) & mdxRMS (old) \\
\hline Trp53 & $1.00 \pm 0.26$ & $1.11 \pm 0.11$ & $0.70 \pm 0.07$ & $1.28 \pm 0.10$ & $6.42 \pm 0.53^{\star \star \star}$ \\
Mdm2 & $1.00 \pm 0.31$ & $0.72 \pm 0.05$ & $0.93 \pm 0.08$ & $1.15 \pm 0.12$ & $1.46 \pm 0.14$ \\
Pax3 & $1.00 \pm 0.02$ & $1.14 \pm 0.22$ & $6.28 \pm 1.45$ & $4.45 \pm 1.30$ & $9.52 \pm 2.86^{\star}$ \\
Pax7 & $1.00 \pm 0.24$ & $1.67 \pm 0.25$ & $0.55 \pm 0.08$ & $0.80 \pm 0.05$ & $7.71 \pm 2.58^{\star}$ \\
Fkhr & $1.00 \pm 0.13$ & $0.67 \pm 0.10$ & $0.95 \pm 0.10$ & $0.52 \pm 0.07$ & $0.59 \pm 0.06$ \\
\hline
\end{tabular}

mRNA levels of genes of interest were measured, relative to 18S RNA control, in five different groups: RMS derived from mdx mice and normal skeletal muscles (gastrocnemius) from young and old wild-type (WT) and mdx mice (without tumors). Unpaired two-tailed Student's $t$-test comparisons were done between $\mathrm{mdx}$ (old) and mdxRMS (old) for each gene. ( ${ }^{*} P<0.05$, ${ }^{* * *} P<0.001$ ) The fold change is reported relative to wild-type (young) signal for each gene. Muscles from young mice averaged 3 months of age for each group. Muscles and tumors from old animals averaged 15 months of age for each group. Errors are SEM for $n=7$ to 25 samples per group. 
(about $80 \%$ ) contain such PAX3:FKHR or PAX7:FKHR translocations. ${ }^{46}$

All mdx RMS showed increased expression of both p53 and Mdm2 protein, and about half also showed increased expression of $\mathrm{Rb}$ and Igf2 (Figure 4). p53 protein, on average, was increased in $\mathrm{mdx}$ RMS by $2.8 \pm$ 0.8-fold compared with normal mdx muscle $(P<0.05)$, while $\mathrm{Rb}$ was increased by $2.8 \pm 0.9$-fold $(P<0.05)$. Both increases were normalized to blots re-probed for actin, which was equivalent between conditions ( $\mathrm{mdx}$ RMS was $95 \pm 6 \%$ of control). It was difficult to assess the extent of Mdm2 overexpression, as normal mdx muscles expressed so little protein, but mdx RMS showed a $17 \pm$ 4-fold average increase relative to $\mathrm{mdx}(P<0.001)$. Five of seven mdx RMS analyzed showed increased expression of phosphorylated Akt (phospho-Ser 473) and decreased expression of PTEN. The two mdx RMS that did not show increased phosphoserine 473-Akt showed normal PTEN expression, consistent with the fact that PTEN negatively regulates Akt phosphorylation. ${ }^{58}$ These two samples, however, also showed reduced Akt protein, which would yield the same result. Five of seven tumors also showed increased expression of survivin, an antiapoptosis factor implicated in RMS and in other tumor types. ${ }^{60}$ All tumors expressed desmin at levels approaching those found in control tissues ( $m \mathrm{dx}$ RMS was $73 \pm 6 \%$ of normal mdx muscle signal, $P>0.05$ ), while secondary antibody alone showed no signal on any blot. Other cancer-related proteins (NF1, N-myc) showed no increase in mdx RMS (not shown). Thus, mdx RMS showed expression of oncogene proteins that was similar to that reported in human RMS with regard to phosphoserine473-AKT, PTEN, Igf2, and Rb, but showed an absolute change in the expression of Mdm2 and p53. This argues that p53 and/or Mdm2 may be more directly involved in tumorigenesis in these animals.

As with Pax3, Pax7, and Fkhr, we measured mRNA levels by TaqMan qRT-PCR for p53 and Mdm2 (Table 2). While there was no significant change in Mdm2 levels between tumors and aged-matched control mdx tissue, there was a significant increase in mRNA for p53 (Table 2). Thus, some of the elevation in p53 protein could result from increased Trp53 gene transcription. Indeed, p53 transcription was elevated by more than twofold in six of the seven tumors analyzed for protein changes (Figure 4 ), while none of the same tumors showed similarly elevated Mdm2 transcription. In total, 24 of $25 \mathrm{mdx}$ RMS analyzed had greater than twofold elevation in p53 transcription compared with wild-type skeletal muscle. By contrast, only 3 of 25 total mdx RMS analyzed showed greater than twofold elevation in Mdm2 expression. This suggests that Mdm2 gene amplification, which can occur in pediatric RMS ${ }^{49}$ was not present in most mdx RMS.

We also surveyed expression of proteins that regulate cell death to determine whether such proteins might contribute to the behavior of the mdx RMS (Figure 6). Apoptosis inhibiting factor, Bax, and Bclll showed no significant change relative to $\mathrm{mdx}$ muscle controls, though both Bax and Bclll were elevated in normal mdx skeletal muscle versus wild-type. Five of seven mdx RMS had elevated levels of BID, another promoter of cell death,

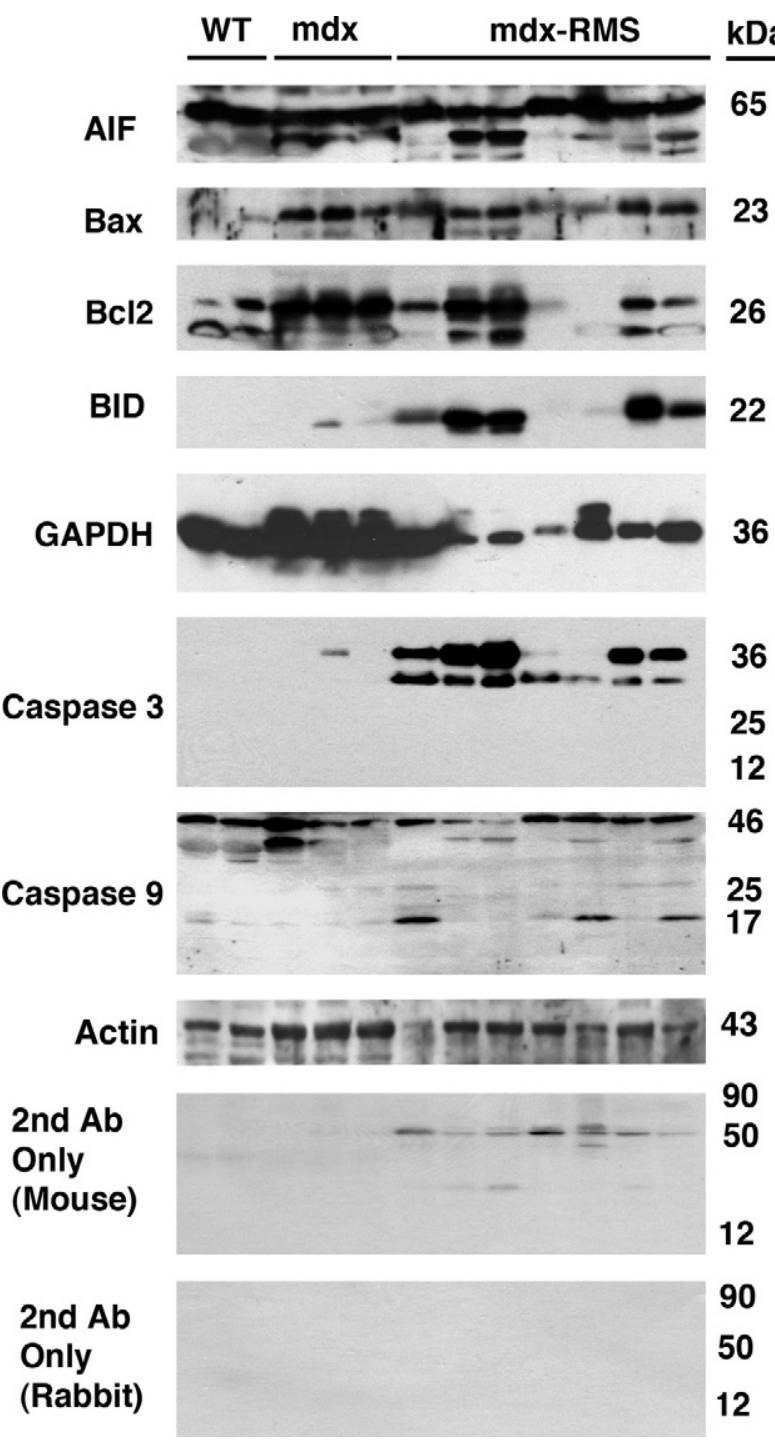

Figure 6. Expression of cell death proteins in mdx RMS and normal mdx and wild-type skeletal muscle. Forty micrograms of whole muscle protein lysate from mdx RMS and mdx and wild-type (WT) skeletal muscle were separated by SDS-PAGE and immunoblotted to show relative expression of proteins involved in the regulation of apoptosis. Most mdx RMS had increased expression of pre-pro caspase 3 (but not $12 \mathrm{kDa}$ or $17 \mathrm{kDa}$ activated forms), BID (a pro-apoptosis factor), and reduced levels of GAPDH (an apoptosis inhibitor). Bax and Bcl-2 were elevated in mdx muscle versus wild-type, but not increased further in mdx RMS. Native molecular weights are: apoptosis inhibiting factor $(65 \mathrm{kDa}), \operatorname{Bax}(23 \mathrm{kDa}), \mathrm{Bcl}-2(26 \mathrm{kDa}), \mathrm{BID}(22 \mathrm{kDa})$, GAPDH $(36 \mathrm{kDa})$, pre-pro caspase $3(36 / 33 \mathrm{kDa})$, pre-pro caspase 9 ( 46 $\mathrm{kDa})$, and actin ( $43 \mathrm{kDa})$.

and six of seven had decreased levels of GAPDH, a protein involved in the glycolysis that has recently been implicated as a negative regulator of apoptosis. ${ }^{82}$ Seven of seven mdx RMS showed elevated levels of caspase 3 expression, but no evidence of activated (cleaved 12 or $17 \mathrm{kDa}$ ) caspase 3 protein, while caspase 9 expression was roughly equivalent between $\mathrm{mdx}$ RMS and mdx samples. As before, secondary antibody alone yielded no specific bands, with the exception of anti-mouse IgG, which bound to endogenous mouse $\mathrm{F}_{\mathrm{C}}$ receptor, and actin protein levels were not changed (Figure 6). These molecular changes point to altered expression of certain 
Table 3. Description of Human TP53 Cancer-Associated Mutations or Deletions in Mouse Trp53 in mdx RMS and Age-Matched Normal mdx Skeletal Muscle

\begin{tabular}{|c|c|c|c|c|c|c|c|c|c|}
\hline Sample & Exon & $\begin{array}{c}\text { mRNA } \\
\text { nt }\end{array}$ & Description & $\begin{array}{l}\text { Wild-type } \\
\text { codon }\end{array}$ & $\begin{array}{l}\text { Mutant } \\
\text { codon }\end{array}$ & $\begin{array}{l}\text { Protein } \\
\text { mouse }\end{array}$ & $\begin{array}{l}\text { Protein } \\
\text { human }\end{array}$ & Effect & $\begin{array}{l}\text { Corresponding mutation ID in } \\
\text { the IARC TP53 database }\end{array}$ \\
\hline Tumor-A & Exon 4 & 321 & $A>G$ & GAA & GGA & E55G & & \\
\hline Tumor-B & Exon 5 & 656 & $A>G$ & ACG & GCG & T167A & T170A & $\begin{array}{l}\text { Missense } \\
\text { Missense } 1293,9320,9971,10517\end{array}$ & 1293, 9320, 9971, 10517 \\
\hline Tumor-A & Exon 5 & 666 & $\mathrm{~T}>\mathrm{C}$ & GTG & GCG & V170A & V173A & Missense & $\begin{array}{l}947,1006,1383,1710,1945 \\
3034,4441,7535,8309 \\
9250,11738,14868,14871 \\
15516,18252,21774,22959\end{array}$ \\
\hline Tumor-46 & Exon 6 & 711 & $\mathrm{~T}>\mathrm{C}$ & CTG & CCG & L185P & L188P & \multirow{2}{*}{$\begin{array}{l}\text { Missense } \\
\text { Missense }\end{array}$} & 20483 \\
\hline Tumor-112 & Exon 6 & 771 & $A>G$ & GAC & GGC & D205G & D208G & & $\begin{array}{l}8493,10968,12631,17796 \\
24099,25352\end{array}$ \\
\hline Tumor-50 & Exon 7 & 890 & $C>T$ & CGC & TGC & $\mathrm{R} 245 \mathrm{C}$ & R248C & \multirow{2}{*}{$\begin{array}{l}\text { Missense } \\
\text { Missense }\end{array}$} & 9913 \\
\hline Tumor-50 & Exon 9 & 1073 & $C>T$ & CCC & TCC & P306S & P309S & & $\begin{array}{l}11454,22236,22608,22672, \\
24559\end{array}$ \\
\hline Tumor-41 & Exon 10 & 1160 & $\mathrm{~T}>\mathrm{C}$ & TTC & СтС & F335L & F338L & \multirow{2}{*}{\multicolumn{2}{|c|}{$\begin{array}{l}\text { Missense } 25823 \\
\text { Deletion }\end{array}$}} \\
\hline Tumor-113 & 11 & $\begin{array}{l}\text { ase pair } \\
\text { sing frar } \\
1 \text { amino }\end{array}$ & $\begin{array}{l}\text { are deleted in } \\
\text { eeshift and pre } \\
\text { acids instead }\end{array}$ & $\begin{array}{l}\text { Exons 8-9 } \\
\text { nature term } \\
\text { f 390) }\end{array}$ & $\begin{array}{l}\text { cleotides } \\
\text { tion of the }\end{array}$ & $\begin{array}{l}1004-1121) \\
\text { protein }\end{array}$ & & & \\
\hline $\begin{array}{l}\text { Normal } \\
\qquad m d x-1121\end{array}$ & Exon 4 & 437 & $G>A$ & GTC & ATC & V94I & V97। & Missense & 23474 \\
\hline
\end{tabular}

Trp53 transcripts from mdx RMS tumors and age-matched normal mdx skeletal muscle were sequenced across exons 2 to 10 . Seven of seven mdxRMS tumors analyzed showed missense mutations known to occur in the homologous region of TP53 in human cancer or deletions. One Trp53 gene deletion was also identified. By contrast, only one of seven normal mdx skeletal muscles analyzed showed any cancer-associated Trp53 mutations. $n=18$ to 25 per condition.

apoptosis factors (survivin, BID, caspase 3, and GAPDH) in $\mathrm{mdx}$ RMS.

We next sequenced cDNA clones from seven of the mdx RMS (same samples as shown in Figure 4) using primers that covered the majority of the p53 (Trp53) exons where human mutations are typically found in various types of cancer (exons 2-10). We identified either deletions or point mutations in p53 transcripts from all (seven of seven) mdx RMS analyzed, while only one of seven age-matched normal mdx skeletal muscles contained a similar cancer-associated p53 mutation (Table $3)$. Of the several dozen clones sequenced for each group, $40 \%$ of mdx RMS clones contained cancer-associated p53 missense mutations or deletions, while only $5 \%$ of normal mdx skeletal muscle samples did. If silent mutations were also included, which would not alter the amino acid coding sequence, the percentage of clones with mutations for the two groups was roughly equal (44\% mdx RMS, $40 \%$ mdx normal). Thus, every mdx RMS analyzed contained transcripts with missense mutations known to occur in human cancer (or a p53 deletion). The one possible exception was the E55G mouse mutation in tumor A (Table 3). Because the human p53 protein contains a 3-aa insertion after this amino acid relative to its alignment with the mouse, the assignment of homology is more tenuous, though the amino acids most likely to represent mouse E55 in human has been shown to contain cancer-associated missense mutations (E56K, ID\#4830, 24294, 23464, ${ }^{75}$ and E56V, ID\#5366 ${ }^{75}$ ). The finding of increased p53 protein in tumors containing inactivating p53 gene mutations is relatively common. ${ }^{83}$

We also performed sequence analysis along the entire length of the Mdm2 coding sequence (exons 2-12). As with p53 (Table 3), we identified more Mdm2 missense mutations in mdx RMS samples (six of seven tumors) than in equivalent number of age-matched normal mdx skeletal muscles (three of seven controls) (Table 4). Here, we were unable to reference an extensive database to determine the relevance of the $\mathrm{Mdm} 2$ missense mutations to human cancer. In addition, we found that five of seven mdx RMS samples expressed a specific Mdm2 splice form lacking exon 3 (Table 4). By contrast, none of the seven normal (age-matched) mdx skeletal muscles contained this splice form, though they did possess other small gene or splice deletions (Table 4). Deletion of exon 3 would eliminate about half of the p53 protein-binding domain. Splice forms of Mdm2 lacking the p53 binding domain have been reported to be specifically associated with cancer ${ }^{84}$ and to stimulate tumor growth. ${ }^{85} \mathrm{In}$ aggregate, $100 \%$ of the almost two dozen mdx RMS clones sequenced showed either missense mutations or altered splicing of Mdm2 (deletion of exon 3). Unlike p53, however, a high percentage $(50 \%)$ of $\mathrm{Mdm} 2$ clones sequence from age-matched normal mdx skeletal muscle also showed missense mutations, altered splicing, or gene deletion. None of the normal mdx samples, however, contained a spliced deletion of exon 3, while $50 \%$ of $\mathrm{mdx}$ RMS clones contained this specific splice form.

\section{Characterization of the DAG Complex in mdx RMS and Human RMS}

Our original intent in understanding $\mathrm{mdx}$ and $\mathrm{Sgca}^{-1-}$ mice emanated from our long-standing interest in the role of the DAG complex in muscular dystrophy. In both the $\mathrm{mdx}$ and the $\mathrm{Sgca}^{-1-}$ models, loss of one component of the DAG complex results in instability or reduced expression of other DAGs. ${ }^{36,37}$ Such changes also appear to correlate with a number of types of cancer ${ }^{4,26-32,35}$ and also can occur during normal skeletal muscle development. ${ }^{86}$ We had previously shown ${ }^{32}$ that pediatric ERMS and ARMS are significantly associated with lowered ex- 
Table 4. Missense Mutations and Altered Splicing of Mdm2 in mdx RMS and Normal mdx Skeletal Muscle

\begin{tabular}{|c|c|c|c|c|c|c|c|}
\hline Sample & Exon & mRNA nt & Description & Wild-type codon & Mutant codon & Protein mouse & Effect \\
\hline Tumor-113 & 5 & 431 & $A>G$ & TAT & TGT & Y60C & Missense \\
\hline Tumor-A & 5 & 470 & $A>C$ & CAC & $\mathrm{CCC}$ & $\mathrm{H} 73 \mathrm{P}$ & Missense \\
\hline Tumor-A & 6 & 551 & $A>G$ & TAT & TGT & Y100C & Missense \\
\hline Tumor-50 & 6 & 565 & $A>G$ & AGA & GGA & R105G & Missense \\
\hline Tumor-113 & 7 & 619 & $A>G$ & AGA & GGA & $\mathrm{R} 123 \mathrm{G}$ & Missense \\
\hline Tumor-46 & 7 & 650 & $A>G$ & AAG & $A G G$ & $\mathrm{~K} 133 \mathrm{R}$ & Missense \\
\hline Tumor-50 & 8 & 655 & $C>A$ & CCT & ACT & P135T & Missense \\
\hline Tumor-41 & 9 & 821 & $\mathrm{~T}>\mathrm{C}$ & CTG & CCG & L190P & Missense \\
\hline Tumor-41 & 10 & 1018 & $G>A$ & GAT & AAT & D256N & Missense \\
\hline Tumor-113 & 10 & 1046 & $A>G$ & GAG & GGG & E265G & Missense \\
\hline Tumor-41 & 12 & 1241 & $A>G$ & GAC & GGC & D330G & Missense \\
\hline Tumor-B & 12 & 1319 & $A>G$ & GAT & GGT & D356G & Missense \\
\hline Normal mdx-1211 & 9 & 901 & $\mathrm{C}>\mathrm{T}$ & $\mathrm{CCC}$ & TCC & P217S & Missense \\
\hline Normal mdx-1211 & 10 & 941 & $\mathrm{C}>\mathrm{G}$ & TCT & TGT & S230C & Missense \\
\hline Normal mdx-1121 & 12 & 1450 & $A>G$ & AGC & GGC & S400G & Missense \\
\hline Normal mdx-791 & 5 & 480 & $\mathrm{~T}>\mathrm{G}$ & TAT & TAG & Y76Stop & Nonsense \\
\hline Tumor-41 & \multicolumn{7}{|c|}{ Exon 3 is skipped, missing first 49 amino acids } \\
\hline Tumor-46 & \multicolumn{7}{|c|}{ Exon 3 is skipped, missing first 49 amino acids } \\
\hline Tumor-46 & \multicolumn{7}{|c|}{ Exon 3 is skipped, missing first 49 amino acids } \\
\hline Tumor-50 & \multicolumn{7}{|c|}{ Exon 3 is skipped, missing first 49 amino acids } \\
\hline Tumor-112 & \multicolumn{7}{|c|}{ Exon 3 is skipped, missing first 49 amino acids } \\
\hline Tumor-112 & \multicolumn{7}{|c|}{ Exon 3 is skipped, missing first 49 amino acids } \\
\hline Tumor-112 & \multicolumn{7}{|c|}{ Exon 3 is skipped, missing first 49 amino acids } \\
\hline Tumor-B & \multicolumn{7}{|c|}{ Exon 3 is skipped, missing first 49 amino acids } \\
\hline Tumor-B & \multicolumn{7}{|c|}{ Exon 3 is skipped, missing first 49 amino acids } \\
\hline Tumor-113 & \multicolumn{7}{|c|}{$\begin{array}{l}83 \text { base pairs are deleted in Exon } 9 \text { (nucleotides 764-846), causing frameshift and premature termination } \\
\text { of the protein ( } 178 \text { amino acids instead of full-length } 489 \text { amino acids) }\end{array}$} \\
\hline Normal mdx-1011 & \multicolumn{7}{|c|}{48 base pairs are deleted in Exon 10 (nucleotides 913-960), causing deletion of 16 amino acids (221-236) } \\
\hline Normal mdx-1211 & \multicolumn{7}{|c|}{$\begin{array}{l}\text { Exon } 5 \text { is skipped, causing frameshift, and early termination of the protein ( } 75 \text { amino acids instead of } \\
\text { full-length } 489 \text { amino acids) }\end{array}$} \\
\hline Normal mdx-1211 & \multicolumn{7}{|c|}{$\begin{array}{l}99 \text { base pairs are deleted in Exon } 12 \text { (nucleotides 1235-1333), causing frameshift and deletion of } 34 \text { amino } \\
\text { acids (328-361) and introduction of } Q \text { in the place of } 34 \text { amino acids }\end{array}$} \\
\hline Normal mdx-1212 & \multicolumn{7}{|c|}{$\begin{array}{l}211 \text { base pairs are deleted in Exon } 12 \text { (nucleotides 1233-1443), causing frameshift and premature } \\
\text { termination of the protein ( } 326 \text { amino acids instead of full-length } 489 \text { amino acids) }\end{array}$} \\
\hline
\end{tabular}

Mdm2 transcripts from mdx RMS tumors and age-matched mdx normal skeletal muscle were sequenced. Missense mutations and altered splicing and/or gene deletions were identified. Six of seven mdx RMS tumors showed missense mutations, and three of seven normal mdx muscles did. Five of seven mdx RMS also showed a splicing of exon 3, deleting a 49 amino acid (aa) portion of the p53 binding domain, while none of the normal mdx muscles did. Three of seven normal aged mdx skeletal muscles did, however, show other gene deletions and/or altered splicing. $n=18$ to 22 per condition.

pression of glycosylated $\alpha$ dystroglycan, but have normal expression of $\beta$ dystroglycan, a protein co-translated with $\alpha$ dystroglycan from the DAG1 gene. ${ }^{9,87}$ Reduced or altered glycosylation of $\alpha$ dystroglycan is significant because it correlates with loss of extracellular matrix binding, one of the principal functions of the DAG complex. ${ }^{88}$ Reduced glycosylation of $\alpha$ dystroglycan also correlates with earlier stages of muscle development. ${ }^{86}$ Changed glycosylation of $\alpha$ dystroglycan is usually demonstrated as loss of binding of monoclonal antibodies, such as $1 \mathrm{H} 6{ }^{89}$ that recognize the glycans required for extracellular matrix binding, ${ }^{18}$ or by reduced migration of the glycoprotein on SDS-PAGE gels. ${ }^{86,89}$ Therefore, we asked whether similar changes in $\alpha$ dystroglycan expression occurred in mdx RMS (Figure 7). Four out of seven mdx RMS tumors showed lowered (>50\%) expression of glycosylated $\alpha$ dystroglycan (using $\mathrm{IIH6}$ as a probe), while no mdx RMS showed reduced expression of $\beta$ dystroglycan. Indeed, all mdx RMS studied showed increased expression of a higher molecular weight form of $\beta$ dystroglycan that has previously been described by Guttridge ${ }^{87}$ and colleagues to be present in mdx muscles with tumors. In addition, four of seven mdx RMS showed reduced expression of native $(50 \mathrm{kDa}) \alpha$ sarcoglycan (Figure 7). Thus, roughly half of $\mathrm{mdx}$ RMS showed a deficit in the DAG complex proteins, a number similar to our previous studies on human RMS. ${ }^{32}$ Reduced expression of $\alpha$ dystroglycan and $\alpha$ and $\beta$ sarcoglycan was confirmed by immunostaining. All mdx RMS showed high membrane immunostaining using antibodies to $\beta$ dystroglycan, while many showed reduced staining using antibodies to $\alpha$ dystroglycan and $\alpha$ and $\beta$ sarcoglycan (Figure 8).

Because we had identified RMS in mice deficient in dystrophin (mdx) or $\alpha$ sarcoglycan $\left(\mathrm{Sgca}^{-1-}\right)$, we also wanted to understand the expression of these proteins in human RMS. We first compared protein expression of four snap frozen RMS and two normal skeletal muscle samples by immunoblotting (Figure 9). All RMSs (four of four) had reduced expression of both dystrophin and $\alpha$ sarcoglycan protein. RMS signal for dystrophin protein was $30 \pm 9 \%$ of wild-type and $\alpha$ sarcoglycan signal was $14 \pm 5 \%$ of wild-type ( $P<0.05$ for both, normalized to actin). Expression of both proteins was close to being undetectable for three of four RMS, while one sample showed significant (albeit still reduced) expression. We 


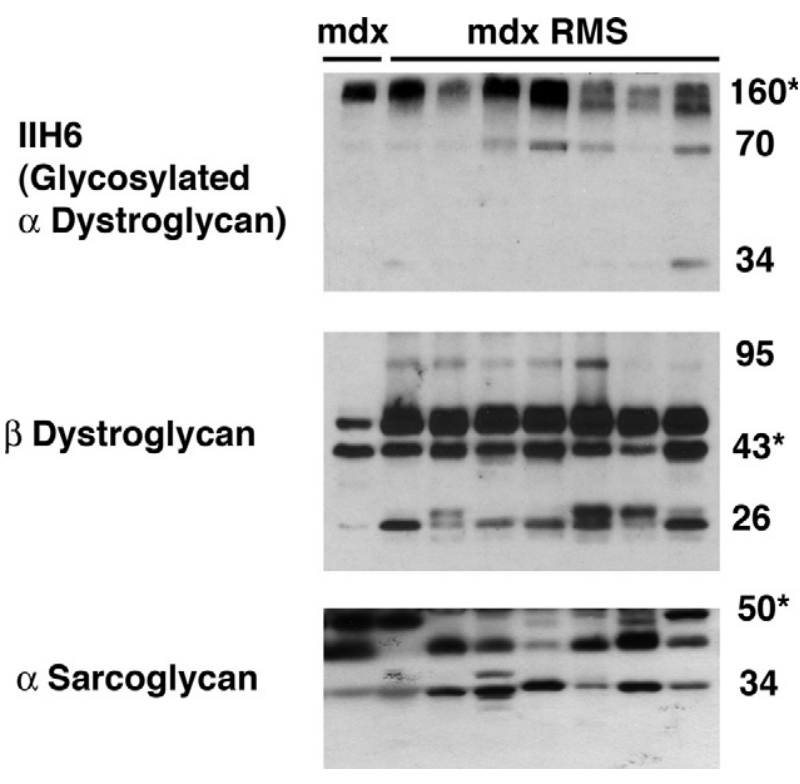

Figure 7. Reduced expression of glycosylated $\alpha$ dystroglycan and $\alpha$ sarcoglycan in mdx RMS. Forty micrograms of total cell protein was compared for expression of glycosylated $\alpha$ dystroglycan (using IIH6), $\beta$ dystroglycan, or $\alpha$ sarcoglycan. Glycosylated $\alpha$ dystroglycan expression and $\alpha$ sarcoglycan protein expression were reduced in about half of mdx RMS, while $\beta$ dystroglycan was not. Asterisks indicate the molecular weight of native full-length protein. Native molecular weights are: $\alpha$ dystroglycan (160 kDa), $\beta$ dystroglycan (43 kDa), $\alpha$ sarcoglycan $(50 \mathrm{kDa})$.

could not determine whether this one sample contained normal muscle tissue taken along with the tumor at the border of the resection, which could explain such a finding.
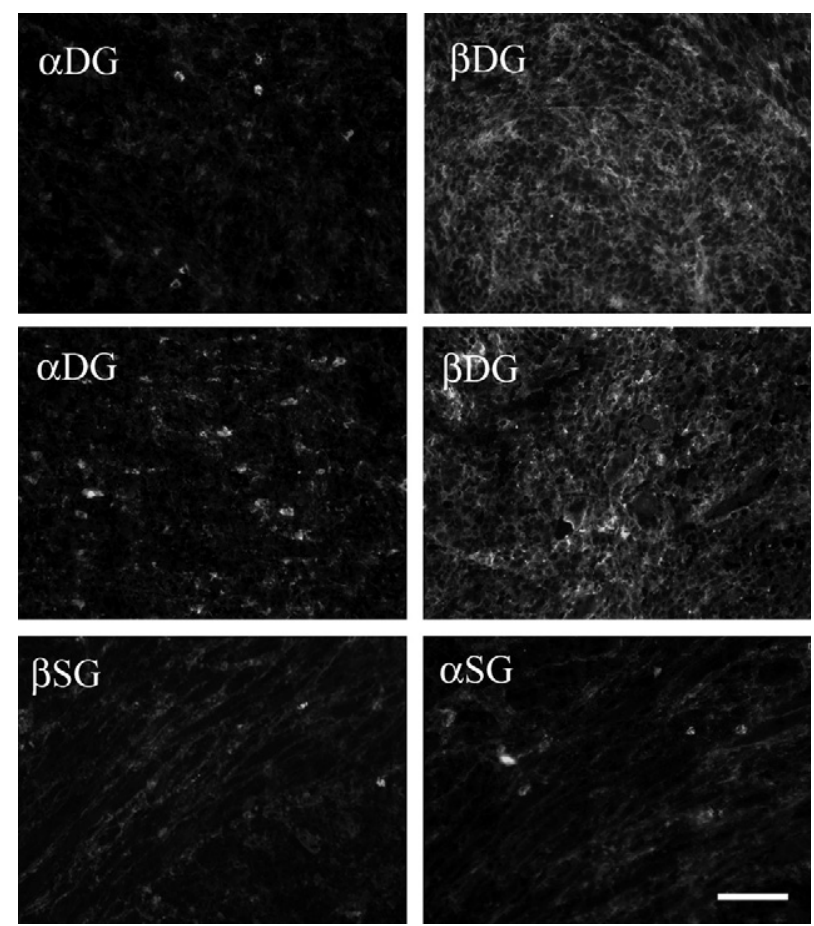

Figure 8. $\alpha$ Dystroglycan, and $\alpha$ and $\beta$ sarcoglycan immunostaining are reduced in mdx RMS. Tumor sections were immunostained with antibodies to dystroglycans or sarcoglycans. Variably decreased expression of $\alpha$ dystroglycan (IIH6) and $\alpha$ and $\beta$ sarcoglycan were found in mdx RMS, while $\beta$ dystroglycan was always strongly expressed. Scale bar $=100 \mu \mathrm{m}$.
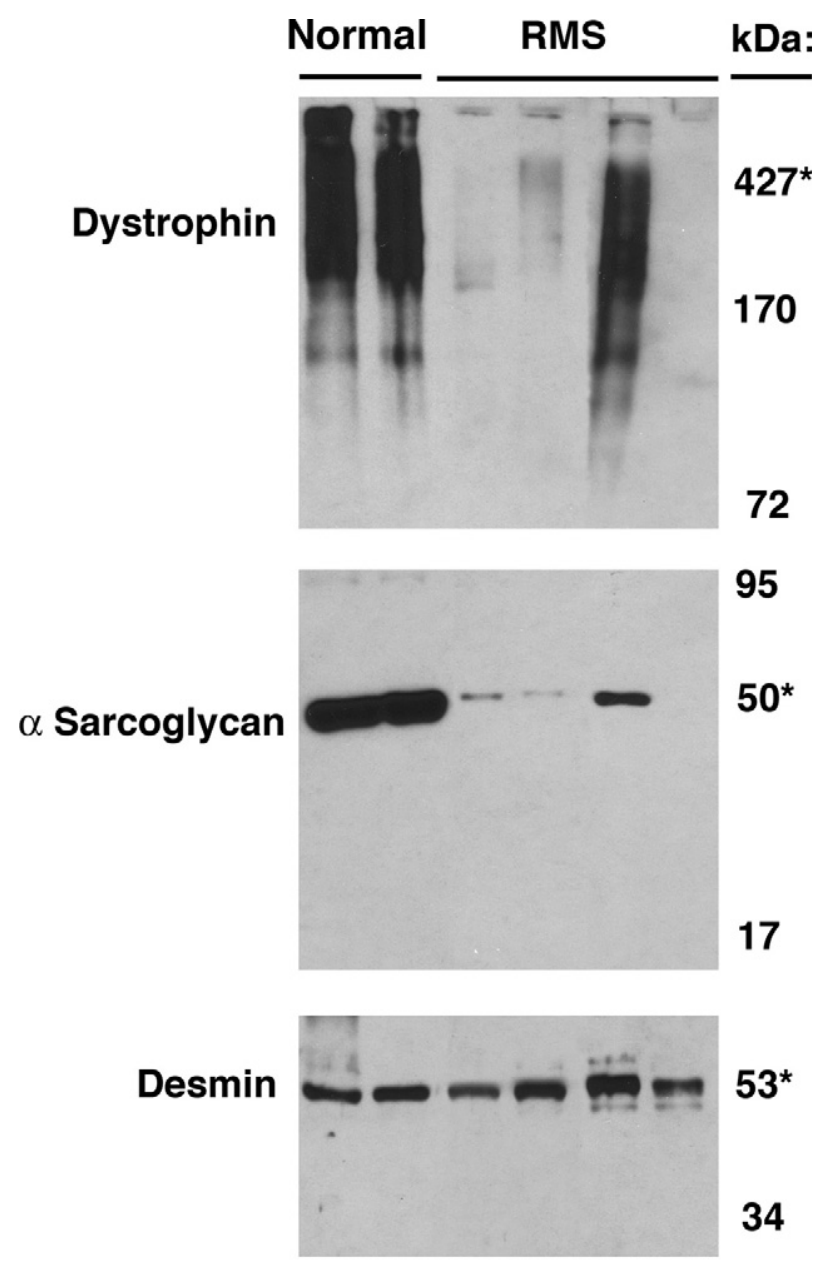

$53^{*}$

\section{Actin}

34

Figure 9. Expression of dystrophin and $\alpha$ sarcoglycan are reduced in human RMS. Forty micrograms of whole cell protein was extracted from normal pediatric human muscle (normal) or from pediatric human RMS (subtype unspecified), separated by SDS-PAGE, and blotted for dystrophin, $\alpha$ sarcoglycan, desmin, or actin. Asterisks indicate molecular weight of native full-length protein: dystrophin $(427 \mathrm{kDa}), \alpha$ sarcoglycan $(50 \mathrm{kDa})$, desmin $(53 \mathrm{kDa})$, and actin $(43 \mathrm{kDa})$.

To clarify this further, we next immunostained RMS tissue arrays bearing normal human skeletal muscle and sections from pediatric ERMS and ARMS with monoclonal antibodies that bind dystrophin (Figure 10). We first characterized staining of available human-specific dystrophin and $\alpha$ sarcoglycan monoclonal antibodies using sections from formalin-fixed, paraffin-embedded, normal muscle after antigen retrieval. Unfortunately, antibodies to $\alpha$ sarcoglycan and one antibody to dystrophin (Dys3) did not stain fixed normal muscle. Two dystrophin antibodies (Dys1 and Dys2), however, did stain reproducibly. Dys 1 recognizes a centrally located portion of the rod domain of the dystrophin protein, while Dys2 recognizes the extreme C-terminal peptide of the protein. Both antibodies were used to stain tissue arrays containing normal skeletal muscle and multiple cases of ARMS or ERMS. We found very high immunostaining of normal muscle with Dys1 in all instances (Figure 10 and Table 5). 

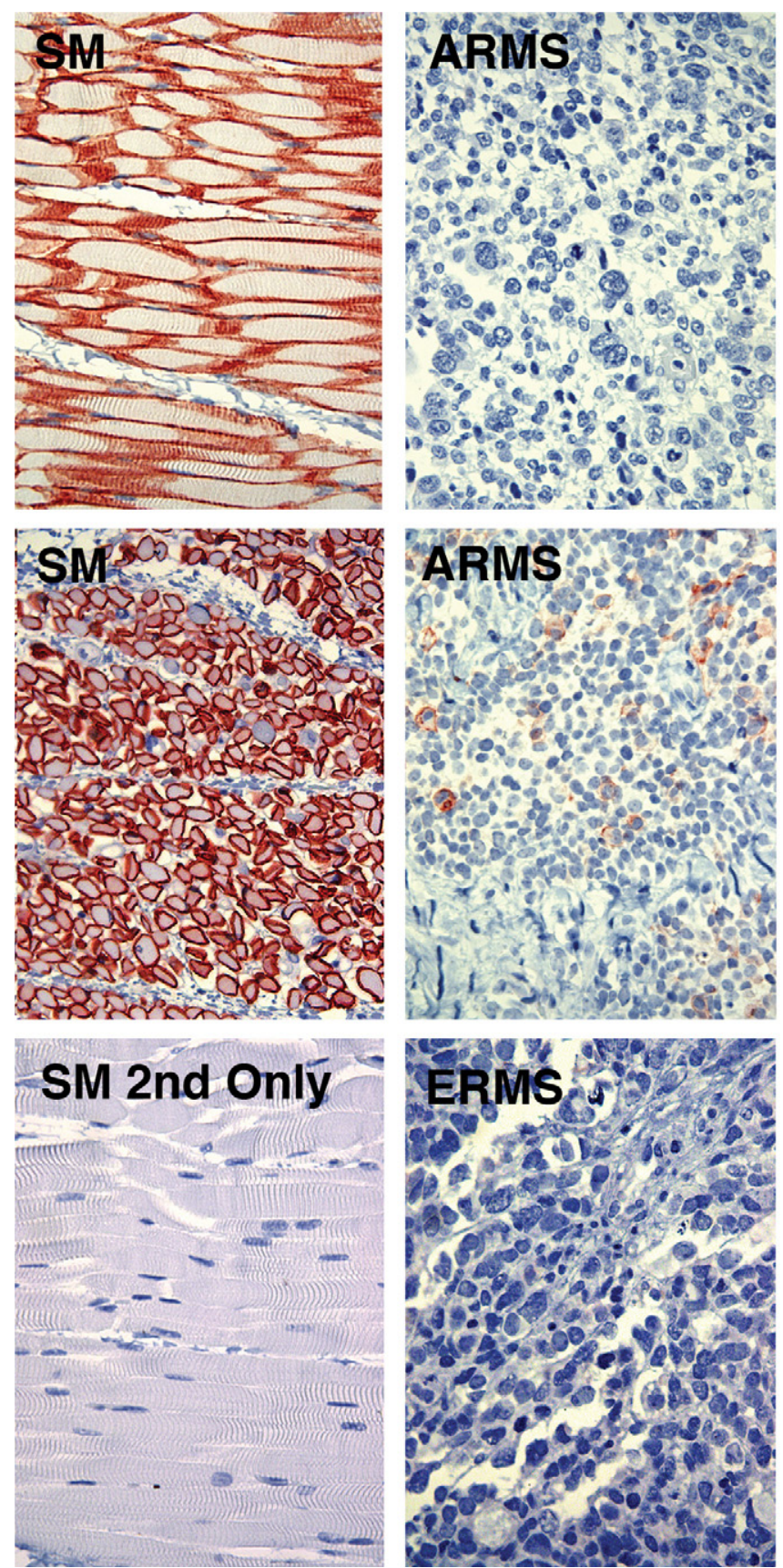
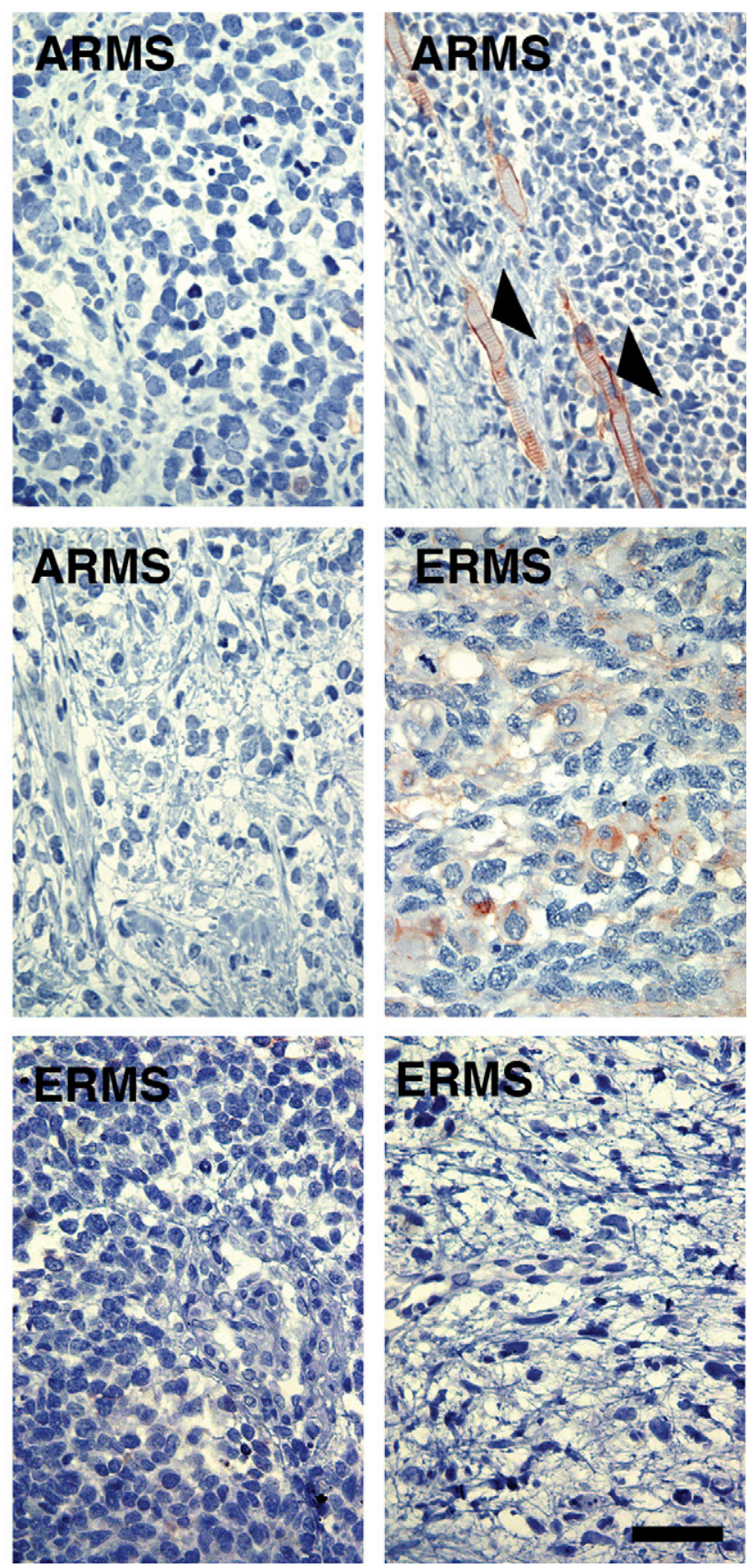

Figure 10. Dystrophin is not expressed in most pediatric RMS, regardless of subtype. Tissue arrays bearing sections of pediatric normal skeletal muscle (SM), embryonal rhabdomyosarcoma (ERMS), or alveolar rhabdomyosarcoma (ARMS) were stained with Dys1, an antibody to dystrophin. All SM stained strongly along the sarcolemmal membranes of myofibers, the normal location of dystrophin protein, whereas almost no RMS, either ERMS or ARMS, were stained. When RMS did express dystrophin, it was present only in a small minority of the tumor cells within the section. Skeletal myofibers within RMS sections (arrowheads), however, stained strongly for dystrophin. Scale bar $=100 \mu \mathrm{m}$.

Additionally, we observed high staining of normal muscle when it was present within RMS sections (Figure 10). By contrast, we observed no Dys1 staining of tumor cells in the majority of RMS cases (Figure 10 and Table 5). Thirty of 39 ARMS and 29 of 32 ERMS were scored as 0 (less than $5 \%$ of tumor cells stained) for Dys 1 staining by all three investigators performing the analysis, with almost all of these cases showing undetectable tumor cell staining. Of the tumors scored as positive, none exceeded an average ranking of 1 , which indicates 5 to $25 \%$ of tumor cells stained, while all normal muscle samples exceeded this level. Dys2 staining, while present in normal muscle, did not typically give as strong a signal (not shown). In addition, Dys2 was scored higher than Dys 1 in the ARMS samples, but the average level of staining was still below 1. When Dys2 staining was elevated, it was not present at the membrane, where dystrophin is normally expressed, but showed broad staining throughout the cytoplasm (not shown). As such, this may reflect artifactual staining or expression of a cleaved, nonfunctional, dystrophin pro- 
Table 5. Scoring of Dystrophin Immunostaining in Embryonal and Alveolar Pediatric

Rhabdomyosarcoma (RMS) and Normal Pediatric Skeletal Muscle

\begin{tabular}{lcl}
\hline \multicolumn{1}{c}{ Sample } & Dys 1 staining & Dys 2 staining \\
\hline Normal muscle & $2.63 \pm 0.19$ & $2.68 \pm 0.10$ \\
Alveolar RMS & $0.2 \pm 0.08^{\star \star *}$ & $0.72 \pm 0.11^{\star * *}$ \\
Embryonal RMS & $0.08 \pm 0.05^{\star \star *}$ & $0.11 \pm 0.02^{\star * *}$ \\
\hline
\end{tabular}

Tissue microarrays were scored for immunostaining using Dys 1 and Dys2 antibodies in normal muscle, alveolar RMS, and embryonal RMS. Each tumor was represented between 2 and 7 times on the slide, and was scored blindly by three independent investigators. Scores of 0 (less than $5 \%$ of cells stained): 1 ( $5 \%$ to $25 \%$ of cell stained); 2 ( $25 \%$ to $75 \%$ of cell stained); or 3 (greater than $75 \%$ of cells stained) were given to tumor cells or normal muscle tissue as appropriate. Scores were averaged to yield a single score for each tumor. Scores represent the average of multiple samples per condition (39 alveolar RMS, 32 embryonal RMS, and 5 normal muscle). All increased Dys2 staining in alveolar RMS was due to intracellular staining and not membrane staining. ${ }^{* * *} P<0.001$, ANOVA comparing ARMS or ERMS to normal with post-hoc $t$-test. Errors are SEM.

tein fragment. Regardless, there was a highly significant decrease in dystrophin staining using both antibodies for both ERMS and ARMS, as compared with normal skeletal muscle ( $P<0.001$ for ARMS-normal or ERMS-normal comparisons, analysis of variance with posthoc $t$-test).

\section{Discussion}

We have described the development of late onset ERMS in a subset of a large population of dystrophic mice containing either a mutation in dystrophin $(\mathrm{mdx})$ or a deletion in $\alpha$ sarcoglycan $\left(\mathrm{Sgca}^{-1-}\right)$. These data suggest a connection between the altered expression of the DAG complex, the cause of dystrophy in these animals, and RMS formation or biology. That RMS derives from mice with reduced expression of disparate members of the DAG complex could alternatively suggest that the dystrophic process itself is driving RMS development and not the specific loss of DAG function. The late onset of tumor development, with all tumors occurring after 1 year of age, also supports this notion. Such a conclusion, however, is actually impossible to prove at this point, as expression of DAG proteins and dystrophin in skeletal muscle are tightly linked; sarcoglycan and dystroglycan expression are reduced at the membrane in mdx muscles lacking dystrophin, ${ }^{36}$ while dystrophin and dystroglycan are less stably present in the sarcolemmal membranes of $\alpha$ sarcoglycan-deficient mice. ${ }^{37}$ Thus, it is possible that all such mice would reflect the same overall loss of function in the DAG complex function, regardless of the molecular trigger causing muscular dystrophy.

While there are case reports of RMS occurring in DMD patients, ${ }^{90,91}$ the incidence does not appear to be above what one might expect in the general population for a combination of a rare $\mathrm{X}$-linked neuromuscular disease and a rare childhood cancer. Again, such a conclusion is difficult to extrapolate to the experiments shown here because there are fundamental differences between $\mathrm{mdx}$ mice and DMD patients that could explain such a disparity. Foremost among these is the fact that DMD, unlike muscular dystrophy in mdx mice, is highly associated with muscle wasting. Weakness in DMD patients arises, in large part, from the replacement of muscle tissue with connective tissue or fat. ${ }^{7}$ Given that ERMS is thought to emanate from satellite cells in skeletal muscle, ${ }^{92,93}$ the regenerative pool of myoblasts present within skeletal muscles, such cells likely would become significantly reduced in number as wasting in DMD progressed. By contrast, mdx mice, show little to no muscle wasting, have robust muscle regeneration, ${ }^{80,94}$ and are therefore likely to maintain their satellite cell population to a higher degree than found in DMD muscle with age.

This study is actually the second demonstration of RMS in mdx mice (and the first demonstration in $\alpha$ sarcoglycan-deficient mice). In the original report by Chamberlain and colleagues, a similar incidence of RMS (6\% there vs. $9 \%$ here) and similar late onset to development (>12 months) was found, however, they reported that the tumors were of the alveolar RMS subtype, a conclusion based on the fact that the tumor cells expressed high levels of MyoD and myogenin and also on their histopathology. ${ }^{95}$ As ERMS also express MyoD and myogenin, ${ }^{39}$ the expression of myogenic transcription factors is an inappropriate singular criterion for a diagnosis of ARMS. Using unbiased methods, we unequivocally demonstrate here that all RMS derived from mdx mice are consistent with ERMS: all mdx tumors display both cellular and molecular characteristics consistent with ERMS and show almost no characteristics of ARMS. The level of myogenin and MyoD co-expression within tumor cells is generally low (less than 10\%), tumors display high cellularity with features of differentiated muscle, both features of ERMS, ${ }^{39,40}$ and tumor histology shows almost no evidence of ARMS-like morphology, such as alignment of tumor cells along fibrous septa of collagenous material. Such features were found in a minority of the tumor samples (2 of 26) and then only in a small fraction of the tumor area analyzed. In addition, no transcripts suggestive of Pax3:Fkhr or Pax7:Fkhr translocations were evident in any tumor, a finding found in about $80 \%$ of human ARMS. ${ }^{46}$ A subset of tumors (about $10 \%$ ), however, did display anaplasia, a finding that, like ARMS, is associated with poorer outcomes. ${ }^{6}$ While it is unlikely, it is also possible that some of these tumors could not be ERMS but rather another muscle-derive tumor where muscle proteins (such as MyoD and myogenin) are expressed and muscle differentiation is present (for example, malignant peripheral nerve sheath tumor). ${ }^{84}$ Malignant peripheral nerve sheath tumors, unlike the mdx RMSs studied here, typically show only focal expression of muscle differentiation, whereas we identified muscle differentiation and rhabdomyoblasts to be uniformly present. Other histopathological features also make the diagnosis of malignant peripheral nerve sheath tumors or triton tumors unlikely, though they could in theory represent a minority of cases.

We found reduced to absent expression of dystrophin and in all pediatric RMS we studied, both ARMS and ERMS. Here again, our findings appear to be at odds with some previous literature. Using immunostaining of snapfrozen RMS of undefined subtype, Parham and col- 
leagues reported dystrophin was expressed in 8 of 9 RMS studied and suggested that dystrophin may be a new muscle-specific marker for RMS. ${ }^{96}$ Given that fulllength dystrophin $(427 \mathrm{kDa})$ is not usually expressed in myoblasts (but instead Dp71, ${ }^{97,98}$ a shortened protein transcript that is functionally quite different), it is unlikely that such a late marker of mature muscle differentiation would be present in RMS. While we cannot explain the difference in results, we would note the sections labeled as positive in the previous study only showed staining in a subset of tumor cells. We are confident, based on our simultaneous staining of internal control samples on the same slides that dystrophin is in fact not expressed in almost all human RMS cells, regardless of subtype. Therefore, mdx mice, which have no dystrophin protein expression in almost all skeletal myofibers, ${ }^{20,23}$ mimic this aspect of RMS biology. As such, the absence of dystrophin and DAG complex proteins from RMS could result in loss of function effects that impact tumor behavior. Importantly, loss of $\alpha$ dystroglycan expression, which has been implicated to play roles both in mediating a tumor cell's metastatic potential ${ }^{99}$ and as a tumor suppressor, ${ }^{100}$ appears both in human RMS and in mdx RMS to be variably altered, with half of tumors showing a significant change and half not. ${ }^{32}$ Thus, it is likely that reduced glycosylation of $\alpha$ dystroglycan in RMS is not a primary factor in initiating tumorigenesis, but rather acts as a secondary modifier of tumor behavior (such as alteration of metastatic or growth potential).

By contrast to dystroglycan, our studies on p53 suggest that p53 inactivation is a primary event in mdx RMS tumorogenesis. Cancer-associated p53 mutations were identified in all of the mdx RMS analyzed. This is a finding that is common to a number of double mutant mouse models for ERMS; mice with an inactivating mutation in Trp53 but expressing an activated form of HER-2/neu develop ERMS of the urinary tract (and also salivary carcinomas), ${ }^{101}$ mice deficient in Trp53 with a secondary oncogenic K-ras mutation develop pleomorphic RMS of the lower extremities ${ }^{102}$ (and ERMS in fish ${ }^{92}$ ), mice with a deletion of the tumor suppressor patched $1^{63}$ or suppressor-of-fused ${ }^{64}$ coupled to Trp53 deficiency develop RMS (but also medulloblastoma), and mice deficient in Fos and Trp53 develop RMS of the facial and orbital regions. ${ }^{54}$ These mice stand in contrast to mouse models for ARMS, where most (but not all ${ }^{54}$ ) models use forced expression of Pax3:Fkhr or Pax7:Fkhr fusion proteins. ${ }^{52,70,93,103}$ In addition, we identified missense mutations in Mdm2 as well as alternatively spliced Mdm2 transcripts lacking a portion of the p53 binding domain (exon 3 ) at a higher frequency in mdx RMS than in normal mdx skeletal muscle. As Mdm2 protein normally participates in degrading p53 protein via its E3 ubiquitin ligase activity, ${ }^{104}$ either of these molecular features could also lead to increased p53 protein levels. While one would normally believe this to lower cancer potential, as p53 is a tumor suppressor, the presence of inactivating mutations in p53 would nullify such effects. Additionally, there is evidence that Mdm2 splice forms lacking p53 binding, which appear to be abundant in mdx RMS, may promote tumor growth. ${ }^{85}$ That we saw increased p53 transcription in 24 of $25 \mathrm{mdx}$ RMS analyzed further suggests inappropriate feedback on p53 gene expression is a component of this process. While we only identified one cancerassociated p53 mutation in age-matched normal mdx skeletal muscle (and in $5 \%$ of all clones sequenced), this incidence of mutation closely approximates the incidence of cancer development in mdx mice as a whole $(9 \%)$. As such, we cannot rule out that such inactivating p53 mutations occur in skeletal muscle before tumorigenesis. Additionally, we identified far more missense mutations, altered splicing, or gene deletions in $\mathrm{Mdm} 2$ in normal aged mdx skeletal muscle ( $50 \%$ of clones). Therefore, contributing Mdm2 mutations may also occur in mdx skeletal muscle before tumorigenesis. Additional work will be required to clarify these issues of cause and effect. The engineering Trp53 or Mdm2 mutations (or splice deletions) into dystrophic mice to yield higher tumor incidence and earlier onset could help to generate a more practical RMS model with regard to development of therapies, and such work is currently ongoing.

\section{Acknowledgments}

We thank the late Stephen J. Qualman for helping with the diagnosis of the initially identified ERMS, Marybeth Camboni and Matthew Glass for technical support, and Dawn Chandler for advice on Mdm2 and Trp53 experiments.

\section{References}

1. Durbeej M, Henry MD, Campbell KP: Dystroglycan in development and disease. Curr Opin Cell Biol 1998, 10:594-601

2. Henry MD, Campbell KP: Dystroglycan: an extracellular matrix receptor linked to the cytoskeleton. Curr Opin Cell Biol 1996, 8:625-631

3. Barresi R, Campbell KP: Dystroglycan: from biosynthesis to pathogenesis of human disease. J Cell Sci 2006, 119:199-207

4. Sgambato A, Brancaccio A: The dystroglycan complex: from biology to cancer. J Cell Physiol 2005, 205:163-169

5. Brennan PA, Jing J, Ethunandan M, Gorecki D: Dystroglycan complex in cancer. Eur J Surg Oncol 2004, 30:589-592

6. Parham DM, Ellison DA: Rhabdomyosarcomas in adults and children: an update. Arch Pathol Lab Med 2006, 130:1454-1465

7. Blake DJ, Weir A, Newey SE, Davies KE: Function and genetics of dystrophin and dystrophin-related proteins in muscle. Physiol Rev 2002, 82:291-329

8. Ervasti JM, Campbell KP: Membrane organization of the dystrophinglycoprotein complex. Cell 1991, 66:1121-1131

9. Ibraghimov-Beskrovnaya O, Ervasti JM, Leveille CJ, Slaughter CA, Sernett SW, Campbell KP: Primary structure of dystrophin-associated glycoproteins linking dystrophin to the extracellular matrix. Nature 1992, 355:696-702

10. Chung W, Campanelli JT: WW and EF hand domains of dystrophinfamily proteins mediate dystroglycan binding. Mol Cell Biol Res Commun 1999, 2:162-171

11. Rezniczek GA, Konieczny P, Nikolic B, Reipert S, Schneller D, Abrahamsberg C, Davies KE, Winder SJ, Wiche G: Plectin If scaffolding at the sarcolemma of dystrophic ( $\mathrm{mdx}$ ) muscle fibers through multiple interactions with beta-dystroglycan. J Cell Biol 2007, 176: 965-977

12. Yang B, Jung D, Motto D, Meyer J, Koretzky G, Campbell KP: SH3 domain-mediated interaction of dystroglycan and Grb2. J Biol Chem 1995, 270:11711-11714

13. Zhan Y, Tremblay MR, Melian N, Carbonetto S: Evidence that dystroglycan is associated with dynamin and regulates endocytosis. J Biol Chem 2005, 280:18015-18024 
14. Spence HJ, Dhillon AS, James M, Winder SJ: Dystroglycan, a scaffold for the ERK-MAP kinase cascade. EMBO Rep 2004, 5:484-489

15. Langenbach KJ, Rando TA: Inhibition of dystroglycan binding to laminin disrupts the PI3K/AKT pathway and survival signaling in muscle cells. Muscle Nerve 2002, 26:644-653

16. Sotgia $F$, Lee $H$, Bedford MT, Petrucci T, Sudol M, Lisanti MP: Tyrosine phosphorylation of beta-dystroglycan at its WW domain binding motif. PPxY, recruits SH2 domain containing proteins. Biochemistry 2001, 40:14585-14592

17. Apel ED, Roberds SL, Campbell KP, Merlie JP: Rapsyn may function as a link between the acetylcholine receptor and the agrin-binding dystrophin-associated glycoprotein complex. Neuron 1995, 15:115-126

18. Ervasti JM, Campbell KP: A role for the dystrophin-glycoprotein complex as a transmembrane linker between laminin and actin. J Cell Biol 1993, 122:809-823

19. Michele DE, Campbell KP: Dystrophin-glycoprotein complex: posttranslational processing and dystroglycan function. J Biol Chem 2003, 278:15457-15460

20. Hoffman EP, Brown RH Jr, Kunkel LM: Dystrophin: the protein product of the Duchenne muscular dystrophy locus. Cell 1987, $51: 919-928$

21. Sunada Y, Bernier SM, Kozak CA, Yamada Y, Campbell KP: Deficiency of merosin in dystrophic dy mice and genetic linkage of laminin $\mathrm{M}$ chain gene to dy locus. J Biol Chem 1994, 269:13729-13732

22. Xu H, Christmas $\mathrm{P}$, Wu XR, Wewer UM, Engvall E: Defective muscle basement membrane and lack of M-laminin in the dystrophic dy/dy mouse. Proc Natl Acad Sci USA 1994, 91:5572-5576

23. Sicinski P, Geng Y, Ryder-Cook AS, Barnard EA, Darlison MG, Barnard PJ: The molecular basis of muscular dystrophy in the $\mathrm{mdx}$ mouse: a point mutation. Science 1989, 244:1578-1580

24. Vainzof M, Passos-Bueno MR, Canovas M, Moreira ES, Pavanello RC, Marie SK, Anderson LV, Bonnemann CG, McNally EM, Nigro V Kunkel LM, Zatz M: The sarcoglycan complex in the six autosomal recessive limb-girdle muscular dystrophies. Hum Mol Genet 1996, 5:1963-1969

25. Martin PT: Mechanisms of Disease: congenital muscular dystrophies-glycosylation takes center stage. Nat Clin Pract Neurol 2006, 2:222-230

26. Losasso C, Di Tommaso F, Sgambato A, Ardito R, Cittadini A, Giardina B, Petrucci TC, Brancaccio A: Anomalous dystroglycan in carcinoma cell lines. FEBS Lett 2000, 484:194-198

27. Henry MD, Cohen MB, Campbell KP: Reduced expression of dystroglycan in breast and prostate cancer. Hum Pathol 2001, 32:791-795

28. Muschler J, Levy D, Boudreau R, Henry M, Campbell K, Bissell MJ A role for dystroglycan in epithelial polarization: loss of function in breast tumor cells. Cancer Res 2002, 62:7102-7109

29. Sgambato A, Migaldi M, Montanari M, Camerini A, Brancaccio A, Rossi G, Cangiano R, Losasso C, Capelli G, Trentini GP, Cittadini A: Dystroglycan expression is frequently reduced in human breast and colon cancers and is associated with tumor progression. Am J Pathol 2003, 162:849-860

30. Jing J, Lien CF, Sharma S, Rice J, Brennan PA, Gorecki DC: Aberrant expression, processing and degradation of dystroglycan in squamous cell carcinomas. Eur J Cancer 2004, 40:2143-2151

31. Calogero A, Pavoni E, Gramaglia T, D'Amati G, Ragona G, Brancaccio A, Petrucci TC: Altered expression of alpha-dystroglycan subunit in human gliomas. Cancer Biol Ther 2006, 5:441-448

32. Martin LT, Glass M, Dosunmu E, Martin PT: Altered expression of natively glycosylated alpha dystroglycan in pediatric solid tumors. Hum Pathol 2007, 38:1657-1668

33. Beltran-Valero de Bernabe D, Inamori KI, Yoshida-Moriguchi T, Weydert CJ, Harper HA, Willer T, Henry MD, Campbell KP: Loss of alphadystroglycan laminin binding in epithelium-derived cancers is caused by silencing of large. J Biol Chem 2009, 285:11279-11284

34. Sgambato A, Di Salvatore MA, De Paola B, Rettino A, Faraglia B, Boninsegna A, Graziani C, Camerini A, Proietti G, Cittadini A: Analysis of dystroglycan regulation and functions in mouse mammary epithelial cells and implications for mammary tumorigenesis. J Cell Physiol 2006, 207:520-529

35. Singh J, Itahana Y, Knight-Krajewski S, Kanagawa M, Campbell KP, Bissell MJ, Muschler J: Proteolytic enzymes and altered glycosylation modulate dystroglycan function in carcinoma cells. Cancer Res 2004, 64:6152-6159

36. Matsumura K, Ervasti JM, Ohlendieck K, Kahl SD, Campbell KP:
Association of dystrophin-related protein with dystrophin-associated proteins in mdx mouse muscle. Nature 1992, 360:588-591

37. Duclos F, Straub V, Moore SA, Venzke DP, Hrstka RF, Crosbie RH Durbeej M, Lebakken CS, Ettinger AJ, van der Meulen J, Holt KH, Lim LE, Sanes JR, Davidson BL, Faulkner JA, Williamson R, Campbel KP: Progressive muscular dystrophy in alpha-sarcoglycan-deficient mice. J Cell Biol 1998, 142:1461-1471

38. Arndt CA, Crist WM: Common musculoskeletal tumors of childhood and adolescence. N Engl J Med 1999, 341:342-352

39. Morotti RA, Nicol KK, Parham DM, Teot LA, Moore J, Hayes J, Meyer W, Qualman SJ: An immunohistochemical algorithm to facilitate diagnosis and subtyping of rhabdomyosarcoma: the Children's Oncology Group experience. Am J Surg Pathol 2006, 30:962-968

40. Parham DM: Pathologic classification of rhabdomyosarcomas and correlations with molecular studies. Mod Pathol 2001, 14:506-514

41. Davis RJ, D'Cruz CM, Lovell MA, Biegel JA, Barr FG: Fusion of PAX7 to FKHR by the variant $t(1 ; 13)(p 36 ; q 14)$ translocation in alveolar rhabdomyosarcoma. Cancer Res 1994, 54:2869-2872

42. Barr FG, Galili N, Holick J, Biegel JA, Rovera G, Emanuel BS: Rearrangement of the PAX3 paired box gene in the paediatric solid tumour alveolar rhabdomyosarcoma. Nat Genet 1993, 3:113-117

43. Barr FG: Gene fusions involving PAX and FOX family members in alveolar rhabdomyosarcoma. Oncogene 2001, 20:5736-5746

44. Koufos A, Hansen MF, Copeland NG, Jenkins NA, Lampkin BC, Cavenee WK: Loss of heterozygosity in three embryonal tumours suggests a common pathogenetic mechanism. Nature 1985, 316:330-334

45. Anderson J, Gordon A, McManus A, Shipley J, Pritchard-Jones K: Disruption of imprinted genes at chromosome region 11p15.5 in paediatric rhabdomyosarcoma. Neoplasia 1999, 1:340-348

46. Sorensen PH, Lynch JC, Qualman SJ, Tirabosco R, Lim JF, Maurer HM, Bridge JA, Crist WM, Triche TJ, Barr FG: PAX3-FKHR and PAX7-FKHR gene fusions are prognostic indicators in alveolar rhabdomyosarcoma: a report from the children's oncology group. J Clin Oncol 2002, 20:2672-2679

47. Li FP, Fraumeni JF Jr: Rhabdomyosarcoma in children: epidemiologic study and identification of a familial cancer syndrome. J Natl Cancer Inst 1969, 43:1365-1373

48. Anderson J, Gordon A, Pritchard-Jones K, Shipley J: Genes, chromosomes, and rhabdomyosarcoma. Genes Chromosomes Cancer 1999, 26:275-285

49. Taylor AC, Shu L, Danks MK, Poquette CA, Shetty S, Thayer MJ Houghton PJ, Harris LC: P53 mutation and MDM2 amplification frequency in pediatric rhabdomyosarcoma tumors and cell lines. Med Pediatr Oncol 2000, 35:96-103

50. Felix CA, Kappel CC, Mitsudomi T, Nau MM, Tsokos M, Crouch GD, Nisen PD, Winick NJ, Helman LJ: Frequency and diversity of p53 mutations in childhood rhabdomyosarcoma. Cancer Res 1992, 52:2243-2247

51. Takahashi Y, Oda Y, Kawaguchi K, Tamiya S, Yamamoto H, Suita S, Tsuneyoshi M: Altered expression and molecular abnormalities of cell-cycle-regulatory proteins in rhabdomyosarcoma. Mod Pathol 2004, 17:660-669

52. Keller C, Arenkiel BR, Coffin CM, El-Bardeesy N, DePinho RA, Capecchi MR: Alveolar rhabdomyosarcomas in conditional Pax3: Fkhr mice: cooperativity of Ink4a/ARF and Trp53 loss of function. Genes Dev 2004, 18:2614-2626

53. Naini S, Etheridge KT, Adam SJ, Qualman SJ, Bentley RC, Counter CM, Linardic CM: Defining the cooperative genetic changes that temporally drive alveolar rhabdomyosarcoma. Cancer Res 2008, 68:9583-9588

54. Sharp R, Recio JA, Jhappan C, Otsuka T, Liu S, Yu Y, Liu W, Anver M, Navid F, Helman LJ, DePinho RA, Merlino G: Synergism between INK4a/ARF inactivation and aberrant HGF/SF signaling in rhabdomyosarcomagenesis. Nat Med 2002, 8:1276-1280

55. Iolascon A, Faienza MF, Coppola B, Rosolen A, Basso G, Della Ragione F, Schettini F: Analysis of cyclin-dependent kinase inhibitor genes (CDKN2A. CDKN2B, and CDKN2C) in childhood rhabdomyosarcoma, Genes Chromosomes Cancer 1996, 15:217-222

56. Cen L, Hsieh FC, Lin HJ, Chen CS, Qualman SJ, Lin J: PDK-1/AKT pathway as a novel therapeutic target in rhabdomyosarcoma cells using OSU-03012 compound. Br J Cancer 2007, 97:785-791

57. Tomita Y, Morooka T, Hoshida Y, Zhang B, Qiu Y, Nakamichi I, Hamada K, Ueda T, Naka N, Kudawara I, Aozasa K: Prognostic 
significance of activated AKT expression in soft-tissue sarcoma. Clin Cancer Res 2006, 12:3070-3077

58. Wan X, Helman LJ: Levels of PTEN protein modulate Akt phosphorylation on serine 473 , but not on threonine 308 , in IGF-II-overexpressing rhabdomyosarcomas cells. Oncogene 2003, 22:8205-8211

59. Li HG, Wang Q, Li HM, Kumar S, Parker C, Slevin M, Kumar P: PAX3 and PAX3-FKHR promote rhabdomyosarcoma cell survival through downregulation of PTEN. Cancer Lett 2007, 253:215-223

60. Fangusaro JR, Caldas H, Jiang Y, Altura RA: Survivin: an inhibitor of apoptosis in pediatric cancer. Pediatr Blood Cancer 2006, 47:4-13

61. Caldas H, Holloway MP, Hall BM, Qualman SJ, Altura RA: Survivindirected RNA interference cocktail is a potent suppressor of tumour growth in vivo. J Med Genet 2006, 43:119-128

62. Linardic CM, Counter CM: Genetic modeling of Ras-induced human rhabdomyosarcoma. Methods Enzymol 2008, 438:419-427

63. Eichenmuller M, Bauer R, Von Schweinitz D, Hahn H, Kappler R: Hedgehog-independent overexpression of transforming growth factor-beta1 in rhabdomyosarcoma of Patched 1 mutant mice. Int $J$ Oncol 2007, 31:405-412

64. Lee Y, Kawagoe R, Sasai K, Li Y, Russell HR, Curran T, McKinnon PJ: Loss of suppressor-of-fused function promotes tumorigenesis. Oncogene 2007, 26:6442-6447

65. Calzada-Wack J, Schnitzbauer U, Walch A, Wurster KH, Kappler R, Nathrath M, Hahn H: Analysis of the PTCH coding region in human rhabdomyosarcoma. Hum Mutat 2002, 20:233-234

66. Chen CL, Loy A, Cen L, Chan C, Hsieh FC, Cheng G, Wu B, Qualman SJ, Kunisada K, Yamauchi-Takihara K, Lin J: Signal transducer and activator of transcription 3 is involved in cell growth and survival of human rhabdomyosarcoma and osteosarcoma cells. BMC Cancer 2007, 7:111

67. Yang P, Grufferman S, Khoury MJ, Schwartz AG, Kowalski J, Ruymann FB, Maurer HM: Association of childhood rhabdomyosarcoma with neurofibromatosis type I and birth defects. Genet Epidemiol 1995, 12:467-474

68. Taniguchi E, Nishijo K, McCleish AT, Michalek JE, Grayson MH, Infante AJ, Abboud HE, Legallo RD, Qualman SJ, Rubin BP, Keller C: PDGFR-A is a therapeutic target in alveolar rhabdomyosarcoma. Oncogene 2008, 27:6550-6560

69. Wysoczynski M, Miekus K, Jankowski K, Wanzeck J, Bertolone S, Janowska-Wieczorek A, Ratajczak J, Ratajczak MZ: Leukemia inhibitory factor: a newly identified metastatic factor in rhabdomyosarcomas. Cancer Res 2007, 67:2131-2140

70. Keller C, Hansen MS, Coffin CM, Capecchi MR: Pax3:Fkhr interferes with embryonic Pax3 and Pax7 function: implications for alveolar rhabdomyosarcoma cell of origin. Genes Dev 2004, 18:2608-2613

71. Makawita S, Ho M, Durbin AD, Thorner PS, Malkin D, Somers GR: Expression of insulin-like growth factor pathway proteins in rhabdomyosarcoma: IGF-2 expression is associated with translocation-negative tumors. Pediatr Dev Pathol 2008, 12:127-135

72. Zhan S, Shapiro DN, Helman LJ: Activation of an imprinted allele of the insulin-like growth factor II gene implicated in rhabdomyosarcoma. J Clin Invest 1994, 94:445-448

73. Xu R, Chandrasekharan K, Yoon JH, Camboni M, Martin PT: Overexpression of the cytotoxic T cell (CT) carbohydrate inhibits muscular dystrophy in the dyW mouse model of congenital muscular dystrophy 1A. Am J Pathol 2007, 171:181-199

74. Livak KJ, Schmittgen TD: Analysis of relative gene expression data using real-time quantitative PCR and the 2 -delta delta $C(T)$ method. Methods 2001, 25:402-408

75. Petitjean A, Mathe E, Kato S, Ishioka C, Tavtigian SV, Hainaut P. Olivier M: Impact of mutant p53 functional properties on TP53 mutation patterns and tumor phenotype: lessons from recent developments in the IARC TP53 database. Hum Mutat 2007, 28:622-629

76. Smith PL, Lowe JB: Molecular cloning of a murine N-acetylgalactosamine transferase cDNA that determines expression of the $T$ lymphocyte-specific CT oligosaccharide differentiation antigen. J Biol Chem 1994, 269:15162-15171

77. Sheikh KA, Sun J, Liu Y, Kawai H, Crawford TO, Proia RL, Griffin JW, Schnaar RL: Mice lacking complex gangliosides develop Wallerian degeneration and myelination defects. Proc Natl Acad Sci USA 1999, 96:7532-7537

78. Takamiya K, Yamamoto A, Furukawa K, Yamashiro S, Shin M, Okada M, Fukumoto S, Haraguchi M, Takeda N, Fujimura K, Sakae M, Kishikawa M, Shiku H, Aizawa S: Mice with disrupted GM2/GD2 synthase gene lack complex gangliosides but exhibit only subtle defects in their nervous system. Proc Natl Acad Sci USA 1996, 93:10662-10667

79. Hedlund M, Tangvoranuntakul P, Takematsu H, Long JM, Housley GD, Kozutsumi Y, Suzuki A, Wynshaw-Boris A, Ryan AF, Gallo RL, Varki N, Varki A: N-glycolylneuraminic acid deficiency in mice: implications for human biology and evolution. Mol Cell Biol 2007, 27:4340-4346

80. De la Porte S, Morin S, Koenig J: Characteristics of skeletal muscle in mdx mutant mice. Int Rev Cytol 1999, 191:99-148

81. Seale P, Sabourin LA, Girgis-Gabardo A, Mansouri A, Gruss P, Rudnicki MA: Pax7 is required for the specification of myogenic satellite cells. Cell 2000, 102:777-786

82. Hara MR, Snyder SH: Nitric oxide-GAPDH-Siah: a novel cell death cascade. Cell Mol Neurobiol 2006, 26:527-538

83. Levine AJ: p53, the cellular gatekeeper for growth and division. Cell 1997, 88:323-331

84. Bartel F, Taubert $\mathrm{H}$, Harris LC: Alternative and aberrant splicing of MDM2 mRNA in human cancer. Cancer Cell 2002, 2:9-15

85. Fridman JS, Hernando E, Hemann MT, de Stanchina E, CordonCardo C, Lowe SW: Tumor promotion by Mdm2 splice variants unable to bind p53. Cancer Res 2003, 63:5703-5706

86. Leschziner A, Moukhles H, Lindenbaum M, Gee SH, Butterworth J, Campbell KP, Carbonetto S: Neural regulation of alpha-dystroglycan biosynthesis and glycosylation in skeletal muscle. J Neurochem 2000, 74:70-80

87. Acharyya S, Butchbach ME, Sahenk Z, Wang H, Saji M, Carathers M, Ringel MD, Skipworth RJ, Fearon KC, Hollingsworth MA, Muscarella P, Burghes AH, Rafael-Fortney JA, Guttridge DC: Dystrophin glycoprotein complex dysfunction: a regulatory link between muscular dystrophy and cancer cachexia. Cancer Cell 2005, 8:421-432

88. Martin PT: Dystroglycan glycosylation and its role in matrix binding in skeletal muscle. Glycobiology 2003, 13:55R-66R

89. Michele DE, Barresi R, Kanagawa M, Saito F, Cohn RD, Satz JS, Dollar J, Nishino I, Kelley RI, Somer H, Straub V, Mathews KD, Moore SA, Campbell KP: Post-translational disruption of dystroglycan-ligand interactions in congenital muscular dystrophies. Nature 2002 418:417-422

90. Rossbach HC, Lacson A, Grana NH, Barbosa JL: Duchenne muscular dystrophy and concomitant metastatic alveolar rhabdomyosarcoma. J Pediatr Hematol Oncol 1999, 21:528-530

91. Jakab Z, Szegedi I, Balogh E, Kiss C, Olah E: Duchenne muscular dystrophy-rhabdomyosarcoma, ichthyosis vulgaris/acute monoblastic leukemia: association of rare genetic disorders and childhood malignant diseases. Med Pediatr Oncol 2002, 39:66-68

92. Langenau DM, Keefe MD, Storer NY, Guyon JR, Kutok JL, Le X, Goessling W, Neuberg DS, Kunkel LM, Zon LI: Effects of RAS on the genesis of embryonal rhabdomyosarcoma. Genes Dev 2007, 21:1382-1395

93. Ren YX, Finckenstein FG, Abdueva DA, Shahbazian V, Chung B, Weinberg KI, Triche TJ, Shimada H, Anderson MJ: Mouse mesenchymal stem cells expressing PAX-FKHR form alveolar rhabdomyosarcomas by cooperating with secondary mutations. Cancer Res 2008, 68:6587-6597

94. Durbeej M, Campbell KP: Muscular dystrophies involving the dystrophin-glycoprotein complex: an overview of current mouse models. Curr Opin Genet Dev 2002, 12:349-361

95. Chamberlain JS, Metzger J, Reyes M, Townsend D, Faulkner JA Dystrophin-deficient $\mathrm{mdx}$ mice display a reduced life span and are susceptible to spontaneous rhabdomyosarcoma. FASEB J 2007, 21:2195-2204

96. Pinto A, Paslawski D, Sarnat HB, Parham DM: Immunohistochemical evaluation of dystrophin expression in small round cell tumors of childhood. Mod Pathol 1993, 6:679-683

97. Howard PL, Dally GY, Ditta SD, Austin RC, Worton RG, Klamut HJ Ray PN: Dystrophin isoforms DP71 and DP427 have distinct roles in myogenic cells. Muscle Nerve 1999, 22:16-27

98. de Leon MB, Montanez C, Gomez P, Morales-Lazaro SL, TapiaRamirez V, Valadez-Graham V, Recillas-Targa F, Yaffe D, Nudel U, Cisneros B: Dystrophin Dp71 expression is down-regulated during myogenesis: role of Sp1 and Sp3 on the Dp71 promoter activity. J Biol Chem 2005, 280:5290-5299

99. de Bernabe DB, Inamori K, Yoshida-Moriguchi T, Weydert CJ, Harper HA, Willer T, Henry MD, Campbell KP: Loss of alpha-dystroglycan laminin binding in epithelium-derived cancers is caused by silencing of LARGE. J Biol Chem 2009, 284:11279-11284 
100. Bao X, Kobayashi M, Hatakeyama S, Angata K, Gullberg D, Nakayama J, Fukuda MN, Fukuda M: Tumor suppressor function of laminin-binding alpha-dystroglycan requires a distinct beta3-Nacetylglucosaminyltransferase. Proc Natl Acad Sci USA 2009, 106:12109-12114

101. Nanni P, Nicoletti G, De Giovanni C, Croci S, Astolfi A, Landuzzi L, Di Carlo E, lezzi M, Musiani P, Lollini PL: Development of rhabdomyosarcoma in HER-2/neu transgenic p53 mutant mice. Cancer Res 2003, 63:2728-2732
102. Tsumura $H$, Yoshida T, Saito $H$, Imanaka-Yoshida K, Suzuki N: Cooperation of oncogenic K-ras and p53 deficiency in pleomorphic rhabdomyosarcoma development in adult mice. Oncogene 2006 25:7673-7679

103. Galindo RL, Allport JA, Olson EN: A drosophila model of the rhabdomyosarcoma initiator PAX7-FKHR. Proc Natl Acad Sci USA 2006 103:13439-13444

104. Marine JC, Lozano G: Mdm2-mediated ubiquitylation: p53 and beyond, Cell Death Differ 2009, DOI: 10.1038/cdd.2009.68 